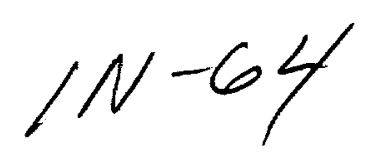

NASA Contractor Report 187168

36900

AIAA-91-2341

p37

\title{
Numerical Simulation of Self-Field MPD Thrusters
}

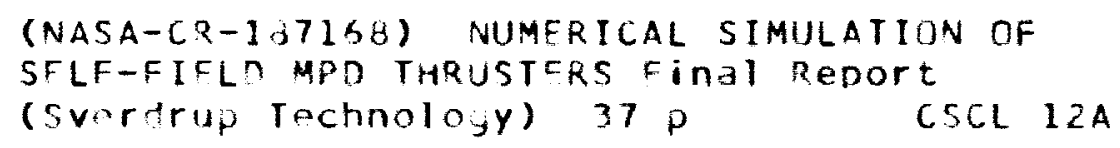

Unclas

G3/64 0036900

Michael R. LaPointe

Sverdrup Technology, Inc.

Lewis Research Center Group

Brook Park, Ohio

August 1991

Prepared for

Lewis Research Center

Under Contract NAS3-25266

\section{N/Sก}

National Aeronautics and

Space Administration 


\title{
Numerical Simulation of Self-Field MPD Thrusters
}

\author{
Michael R. LaPointe \\ Sverdrup Technology, Inc. \\ Lewis Research Center Group \\ Brook Park, Ohio 44142
}

\begin{abstract}
A fully two dimensional magnetohydrodyanamics code has been developed to predict self-field, steady-state MPD thruster performance. The governing equations are outlined, and methods of solution are presented. Model predictions are compared with experimental data for two thruster geometries over a range of discharge currents and mass flow rates. Model limitations are evaluated, and issues concerning quasi-steady versus steady-state thruster comparisons are discussed.
\end{abstract}

\section{Nomenclature}

\begin{tabular}{|c|c|c|c|}
\hline$a_{n}$ & $\begin{array}{l}\text { finite difference coeffs. } \\
\text { thrust coefficient }\left(\mathrm{N} / \mathrm{A}^{2}\right)\end{array}$ & $\begin{array}{l}\mathrm{V} \\
\tilde{w}\end{array}$ & $\begin{array}{l}\text { discharge voltage (V) } \\
\text { weighting factor }\end{array}$ \\
\hline$\vec{B}$ & magnetic field $(\mathrm{T})$ & $\alpha$ & ionization fraction ( $\equiv 1$ ) \\
\hline e & electric charge (C) & $\alpha_{n}$ & finite difference coeffs. \\
\hline $\begin{array}{l}\vec{E} \\
\mathrm{~F}\end{array}$ & $\begin{array}{l}\text { electric field }(\mathrm{V} / \mathrm{m}) \\
\text { thrust }(\mathrm{N})\end{array}$ & $\gamma_{n}$ & \\
\hline $\begin{array}{l}\mathrm{F} \\
\vec{j}\end{array}$ & $\begin{array}{l}\text { thrust }(\mathrm{N}) \\
\text { current density }\left(\mathrm{A} / \mathrm{m}^{2}\right)\end{array}$ & $\Gamma_{m}^{n}$ & differential equation coeffs. \\
\hline $\begin{array}{l}3 \\
\mathrm{~J}\end{array}$ & $\begin{array}{l}\text { current density }\left(\mathrm{A} / \mathrm{m}^{2}\right) \\
\text { discharge current }(\mathrm{A})\end{array}$ & 7 & viscosity $(\mathrm{kg} / \mathrm{m}-\mathrm{s})$ \\
\hline $\mathbf{k}_{B}$ & $\begin{array}{l}\text { discharge current (A) } \\
\text { Boltzmann const. }(\mathrm{J} / \mathrm{K})\end{array}$ & $\begin{array}{l}\eta_{T} \\
\eta_{f f}\end{array}$ & $\begin{array}{l}\text { thruster efficiency } \\
\text { frozen flow efficiency }\end{array}$ \\
\hline m & electron mass $(\mathrm{kg})$ & $\begin{array}{l}\eta_{f f} \\
\kappa_{T}\end{array}$ & $\begin{array}{l}\text { frozen flow efficiency } \\
\text { thermal conductivity (Watt/m-K) }\end{array}$ \\
\hline$\dot{M}$ & ion mass $(\mathrm{kg})$ & & second coeff. of viscosity $(\mathrm{kg} / \mathrm{m}-\mathrm{s})$ \\
\hline $\begin{array}{l}\dot{\mathrm{m}} \\
\mathrm{n}\end{array}$ & mass flow rate $(\mathrm{kg} / \mathrm{s})$ & $\ln \Lambda$ & Coulomb logarithm \\
\hline $\begin{array}{l}\mathrm{n} \\
\mathrm{p}\end{array}$ & $\begin{array}{l}\text { number density }\left(\mathrm{m}^{-3}\right) \\
\text { pressure }(\mathrm{Pa})\end{array}$ & $\mu_{0}$ & permeability of free space \\
\hline $\begin{array}{l}\mathrm{p} \\
\mathrm{P}\end{array}$ & $\begin{array}{l}\text { pressure }(\mathrm{Pa}) \\
\text { power }(\mathrm{W})\end{array}$ & $\xi$ & $\begin{array}{l}\text { density function } \\
\text { mass density }\left(\mathrm{kg} / \mathrm{m}^{3}\right)\end{array}$ \\
\hline$I_{a}$ & anode radius (m) & $\rho$ & $\begin{array}{l}\text { mass density }\left(\mathrm{kg} / \mathrm{m}^{3}\right) \\
\text { electrical conductivity }(\mathrm{mho} / \mathrm{m})\end{array}$ \\
\hline$r_{c}$ & cathode radius (m) & $\tau_{e}$ & $\begin{array}{l}\text { electrical conductivity }(\mathrm{mho} / \mathrm{m}) \\
\text { electron collision time }(\mathrm{s})\end{array}$ \\
\hline $\mathrm{R}$ & gas constant $(\mathrm{J} / \mathrm{K}-\mathrm{mol})$ & $\phi$ & $\begin{array}{l}\text { electron collision time (s) } \\
\text { electric potential }(\mathrm{V})\end{array}$ \\
\hline $\begin{array}{l}R_{M} \\
\Re\end{array}$ & magnetic Reynolds number & $\Phi_{V}$ & viscous dissipation function \\
\hline$\pi$ & mass flow ratio & he & magnetic field stream \\
\hline 1 & source term & $\Psi$ & viscous force vector \\
\hline $\boldsymbol{v}$ & $\begin{array}{l}\text { temperature }(\mathrm{K}) \\
\text { velocity }(\mathrm{m} / \mathrm{s})\end{array}$ & $\omega$ & convergence factor \\
\hline$v_{\text {ex }}$ & $\begin{array}{l}\text { velocity }(\mathrm{m} / \mathrm{s}) \\
\text { exhaust velocity }\end{array}$ & $\begin{array}{l}\omega_{c e} \\
\Omega\end{array}$ & $\begin{array}{l}\text { electron cyclotron frequency }\left(\mathrm{s}^{-1}\right) \\
\text { Hall parameter }\end{array}$ \\
\hline & xhaust velocity & & dert \\
\hline
\end{tabular}




\section{Introduction}

The magnetoplasmadynamic (MPD) thruster is an attractive candidate for orbit raising applications ${ }^{1}$ as well as the high power, long duration missions envisioned by the national Space Exploration Initiative ${ }^{2}$. In its basic form, the MPD thruster consists of a cylindrical cathode surrounded by a concentric anode (Figure 1). An arc struck between the electrodes ionizes a gaseous propellant, and the interaction of the current with self-induced magnetic fields accelerates the plasma to produce thrust. Steady-state MPD thrusters have been operated at power levels approaching $600 \mathrm{~kW}$, while pulsed, quasi-steady devices have operated in the megawatt range ${ }^{3}$. The engine is robust, and designed to provide low, continuous thrust at specific impulse values between 1,000 and $10,000 \mathrm{~s}$.

MPD thruster performance is currently limited by low thrust efficiency in the operating regimes of interest ${ }^{3}$. Applied magnetic fields ${ }^{3,4}$ and flared electrodes ${ }^{5}$ have been shown to influence MPD thruster efficiency and specific impulse, but for reasons poorly understood at present. In addition, severe electrode erosion is observed at high values of $J^{2} / \dot{m}$, corresponding to the onset of voltage oscillations and unsteady thruster operation. Several mechanisms have been proposed to explain the onset of oscillations, including anode mass starvation $^{6}$, flow choking due to enhanced back-EMF ${ }^{7,8}$, and the triggering of electrothermal and gradient instabilities as the plasma approaches full ionization ${ }^{3-11}$. Different operating conditions may trigger one or a combination of the proposed mechanisms, limiting thruster performance and lifetime.

Although MPD thrusters have undergone extensive experimental development since the early 1960 ' $\mathrm{s}^{3.12}$, a comprehensive theoretical analysis has been slowed by the complex nature of the coupled electromagnetic and gasdynamic acceleration processes. Transient and steady-state numerical modeling using 1-D, quasi-1-D, and quasi-2-D approximations of the fluid magnetohydrodynamic equations have provided valuable insights into self-field MPD thruster operation ${ }^{13-27}$, but they are by definition constrained in their ability to predict global thruster performance. The removal of such limitations via fully 2-D and quasi-3-D modeling has recently become practical with the emergence of high speed computational facilities, allowing model validation and refinement using the existing experimental data base while in return establishing a theoretical basis to guide further experimentation.

A fully two dimensional, time dependent code for modeling self-field coaxial MPD thrusters is currently under development at the University of Stuttgart ${ }^{28-30}$. The model employs adaptive grid techniques for enhanced spatial resolution near electrode surfaces and incorporates important second order effects such as Hall currents, viscosity, and thermal conductivity. The plasma is assumed to be a fully ionized single fluid, but separate electron and ion temperatures are calculated to provide more accurate estimates of the thermal transport coefficients. The equations are cast into conservative finite volume form and iterated until a steady state condition is reached. Results compare favorably with experimental tests of the Stuttgart ZT-1 and ZT-2 cylindrical thrusters at low values of $J^{2} / \dot{m}$. However, the code and has not been fully tested at values of $J^{2} / \dot{m}$ which correspond to predominantly electromagnetic regimes of thruster operation ${ }^{31}$. Because the code is being developed specifically to support the Stuttgart self-field plasma accelerator activities, no provision has been included for applied magnetic field effects ${ }^{32}$.

Applied magnetic field effects are included in a cylindrical steady-state thruster code developed by Tanaka and Kimura ${ }^{33}$. The electromagnetic field equations are fully two dimensional, assuming axial symmetry for both the current distribution and the imposed applied magnetic field. The equations describing the plasma flow are based on a single-fluid, quasi-1-D approximation, however, and viscous effects are neglected. In addition, the Hall parameter and electrical conductivity are assumed constant throughout the simulation region. The equations were written in a finite element formulation, and a Newton-Raphson iterative scheme was used to solve for the induced magnetic fields and current densities. Runge-Kutta algorithms were used to evaluate the one dimensional flow equations, and the entire process was repeated until the induced magnetic field and the plasma flow velocity coincided with their previous loop values. Calculations were performed at 
discharge currents of $1000 \mathrm{~A}$ and $2000 \mathrm{~A}$ with a constant mass flow rate of $100 \mathrm{mg} / \mathrm{s}$ and applied magnetic field values up to $0.2 \mathrm{~T}$. Although not compared with specific experimental results, the model predicted trends which had been observed experimentally ${ }^{33}$.

A model which incorporates both self-field and applied magnetic field effects is currently being developed at the NASA Lewis Research Center to support a wide range of experimental MPD thruster activities. The fully 2-D steady-state code is based on the single fluid, single temperature MHD equations ${ }^{34}$, which assume axially symmetry but include azimuthal components of momentum, current density, and magnetic field. Viscous effects and Hall terms are included, as are non-constant expressions for the electrical conductivity and thermal conductivity. The plasma is currently assumed to be a fully (singly) ionized perfect gas. The governing MHD equations are written in finite difference formulation and iteratively solved on a uniform rectangular grid. The code is built using modular subroutines to allow for model expansion and refinement with minimal algorithm reconstruction.

The self-field version of the NASA LeRC code is operational, and is discussed in Section II. Applied magnetic field terms, which do not contribute to self-field thruster operation, are retained in the derivative equations for completeness. Experimental comparisons with a coaxial, steady-state thruster and a flared, quasi-steady thruster are presented in Section III, and the paper concludes with a brief summary of results in Section IV.

\section{MPD Thruster Model}

The MPD thruster model presented below is based upon a single fluid, single temperature approximation of the steady-state magnetohydrodynamic (MHD) equations, written in cylindrical coordinates with assumed symmetry about the centerline. Azimuthal components are retained, rendering the code fully twodimensional. The plasma is currently assumed to be fully, singly ionized, and is described by a perfect gas equation of state.

The fluid description is appropriate for the density and temperature regimes of interest in MPD thruster operation $^{35}$, although such a formulation precludes a detailed evaluation of electrode fall potentials, and does not allow for potentially important kinetic effects such as plasma microinstabilities ${ }^{36}$. These limitations can be overcome by incorporating an electrode sheath model to provide boundary conditions for the fluid code (which in turn provides boundary conditions for the sheath model), and by enveloping the effects of microturbulence within modified expressions for the plasma transport coefficients. It is anticipated that such refinements will be included as appropriate models become available.

The steady-state model is adequate for describing thruster behavior in regimes other than the brief transient start-up period or the onset of plasma oscillations associated with thruster instabilities. The startup period is, with proper design, a negligible fraction of the thruster lifetime and may be safely ignored in evaluating steady-state thruster performance. To properly model the onset of thruster instabilities as they evolve from steady-state operation would require a time-dependent plasma kinetics model and significant computational resources. An alternate and efficient near-term method is to develop separate models which predict regimes of operation under which such instabilities might occur, and incorporate those predictions as limiting conditions in the fluid code. MHD codes in turn can provide information on plasma conditions preceding the onset of thruster instability, as starting conditions for the instability models. While no single code can hope to model every effect, a proper combination of models can provide the understanding necessary for successful MPD thruster development.

With this brief introduction, the equations incorporated into the self-field MPD thruster model are presented below.

IIa. Electromagnetic Field Equations. 
The basic set of electromagnetic equations includes the full complement of Maxwell's equations:
(a) $\nabla \cdot \vec{B}=0$
(b) $\nabla \times \vec{B}=\mu_{0} \vec{j}$
(c) $\nabla \cdot \vec{E}=\rho_{e} / \epsilon_{0} \approx 0$
(d) $\nabla \times \vec{E}=-\frac{\partial \vec{B}}{\partial t}=0$

which incorporate the steady-state, single fluid plasma approximations. A general Ohm's law of the form:

$$
\vec{j}=\sigma[\vec{E} \div(\vec{v} \times \vec{B})]-\frac{\Omega}{B}(\vec{j} \times \vec{B})
$$

is used to relate the current density $\vec{j}$ to the plasma velocity $\vec{v}$ and the electric $(\vec{E})$ and magnetic $(\vec{B})$ fields. Ion slip terms are neglected due to the assumption of full ionization. The electrical conductivity $\sigma$ is given by the classical Spitzer-Harm conductivity for a fully ionized plasma ${ }^{34}$ :

$$
\sigma=1.53 \times 10^{-2} \frac{T^{3 / 2}}{\ln \Lambda}
$$

where $T$ is the temperature in degrees-Kelvin, $\ln \Lambda$ is the Coulomb logarithm:

$$
\ln \Lambda \approx 23-\ln \left[\frac{1.22 \times 10^{3} n^{1 / 2}}{T^{3 / 2}}\right]
$$

and $n$ is the plasma number density expressed in particles per cubic meter. The Hall parameter $\Omega$ is the product of the electron cyclotron frequency $\left(\omega_{\mathrm{ce}}\right)$ and the electron collision time $\left(\tau_{e}\right)$ :

$$
\begin{aligned}
\Omega=\omega_{r e} \tau_{e} & =\left(\frac{e B}{m}\right) \cdot\left(\frac{m \sigma}{n e^{2}}\right) \\
& =9.6 \times 10^{16}\left(\frac{T^{3 / 2} B}{Z n \ln \Lambda}\right)
\end{aligned}
$$

where $m$ is the electron mass, $e$ is the electron charge, and $B$ is the magnitude of the local magnetic field.

Equation 2 may be rearranged to solve for the electric field distribution:

$$
\vec{E}=-\nabla \phi=\frac{1}{\sigma}\left[\vec{j}+\frac{\Omega}{B}(\vec{j} \times \vec{B})\right]-(\vec{v} \times \vec{B})
$$

whose components are given by:

$$
\begin{aligned}
& E_{\mathrm{r}}=-\frac{\partial \phi}{\partial r}=\frac{1}{\sigma}\left[j_{r}+\frac{\Omega}{B}\left(j_{\theta} B_{z}-j_{z} B_{\theta}\right)\right]-\left(v_{\theta} B_{z}-v_{z} B_{\theta}\right) \\
& E_{\theta}=-\frac{\partial \phi}{\partial \theta} \equiv 0 \\
& E_{z}=-\frac{\partial \phi}{\partial z}=\frac{1}{\sigma}\left[j_{z}+\frac{\Omega}{B}\left(j_{r} B_{\theta}-j_{\theta} B_{r}\right)\right]-\left(v_{r} B_{\theta}-v_{\theta} B_{r}\right)(7 c)
\end{aligned}
$$

The radial electric field is integrated from cathode to anode to find the potential drop $\phi$ across the plasma. The divergence of Eq. 6 may be used to generate a Poisson equation for the potential, or assuming quasineutrality a simple Laplace equation may be solved to give the potential distribution, with the calculated plasma fall providing the necessary boundary conditions. The first method is more rigorously correct, while the second method is computationally faster. Both methods were tried, and yield identical results for the plasma potential distribution. 
A magnetic transport equation may be derived by combining Maxwell's equations with the generalized Ohm's law:

$$
\begin{aligned}
\nabla \times \vec{E} & =-\frac{\partial \vec{B}}{\partial t} \\
& =\nabla \times\left(\frac{\nabla \times \vec{B}}{\mu_{0} \sigma}\right)+\nabla \times\left[\frac{\Omega}{\mu_{0} \sigma B}((\nabla \times \vec{B}) \times \vec{B})\right]-\nabla \times(\vec{v} \times \vec{B})=0
\end{aligned}
$$

Defining $\beta=\Omega /(\sigma B)$ and $\psi=r B_{\theta}$, the azimuthal component of the above equation can be written:

$$
\frac{\partial^{2} \psi}{\partial r^{2}}+\gamma_{1} \frac{\partial \psi}{\partial r}+\gamma_{2} \frac{\partial \psi}{\partial z}+\gamma_{3} \psi+\frac{\partial^{2} \psi}{\partial z^{2}}=S
$$

where

$$
\begin{aligned}
& \gamma_{1}=-\left(\frac{1}{r}+\frac{1}{\sigma} \frac{\partial \sigma}{\partial r}-\psi \frac{\sigma}{r} \frac{\partial \beta}{\partial z}+\mu_{0} \sigma v_{\tau}\right) \\
& \gamma_{2}=\left(-\frac{1}{\sigma} \frac{\partial \sigma}{\partial z}-\psi \frac{2 \beta \sigma}{r^{2}}+\psi \frac{\sigma}{r} \frac{\partial \beta}{\partial r}+\mu_{0} \sigma v_{z}\right) \\
& \gamma_{3}=-\left(\mu_{0} \sigma\left[\frac{\partial v_{r}}{\partial r}-\frac{v_{r}}{r}+\frac{\partial v_{z}}{\partial z}\right]\right)
\end{aligned}
$$

and the source term $S$ is given by

$$
\begin{aligned}
S & =\sigma r \beta\left[\left(\frac{\partial B_{z}}{\partial z}+\frac{\partial B_{r}}{\partial r}\right)\left(\frac{\partial B_{r}}{\partial z}-\frac{\partial B_{z}}{\partial r}\right)+B_{z}\left(\frac{\partial^{2} B_{r}}{\partial z^{2}}-\frac{\partial^{2} B_{z}}{\partial r \partial z}\right)+B_{r}\left(\frac{\partial^{2} B_{r}}{\partial r \partial z}-\frac{\partial^{2} B_{z}}{\partial r^{2}}\right)\right] \\
& +\sigma r\left[\left(B_{r} \frac{\partial \beta}{\partial r}+B_{z} \frac{\partial \beta}{\partial z}\right)\left(\frac{\partial B_{r}}{\partial z}-\frac{\partial B_{z}}{\partial r}\right)-\left(v_{\theta}\left(\frac{\partial B_{z}}{\partial z}+\frac{\partial B_{r}}{\partial r}\right)+B_{z} \frac{\partial v_{\theta}}{\partial z}+B_{r} \frac{\partial v_{\theta}}{\partial r}\right)\right]
\end{aligned}
$$

For the self-field thruster, the source term reduces to zero. Once the magnetic transport equation is solved for $\psi$, the value of $B_{\theta}$ is readily obtained. The azimuthal magnetic field is a function of the total discharge current $J$, and through the relation $\psi=r B_{\theta} \sim r(J / r) \sim J$, the function $\psi(r, z)=$ constant may be used to represent lines of total enclosed current.

Returning to the Maxwell equations, the radial and axial current densities are obtained from the calculated magnetic field distributions:

$$
\begin{aligned}
& j_{r}=-\frac{1}{\mu_{0}} \frac{\partial B_{\theta}}{\partial z} \\
& j_{z}=\frac{1}{\mu_{0}}\left(\frac{1}{r} \frac{\partial}{\partial r}\left(r B_{\theta}\right)\right)
\end{aligned}
$$

The azimuthal current density $j_{\theta}$ vanishes due to the absence of applied radial or axial magnetic fields in the self-field MPD thruster.

\section{IIb. Fluid Equations.}

The fluid equations are based on the conservation equations of mass, momentum, and energy. Conservation of mass for a compressible fluid is given by:

$$
\nabla \cdot(\rho \vec{v})=0
$$


which can be written:

$$
\frac{\partial\left(r \rho v_{r}\right)}{\partial r}+\frac{\partial\left(r \rho v_{z}\right)}{\partial z}=0
$$

where $\rho$ is the plasma mass density. Defining $\xi=r \rho$, the mass conservation equation takes the simplified form:

$$
\frac{\partial \xi v_{r}}{\partial r}+\frac{\partial \xi v_{z}}{\partial z}=0
$$

which is solved for $\xi$, from which the value of $\rho$ is determined.

Momentum. The conservation of momentum, including viscosity, is expressed in vector form as:

$$
\rho(\vec{v} \cdot \nabla) \vec{v}=-\nabla p+(\vec{j} \times \vec{B})+\vec{\psi}
$$

where $p$ is the plasma pressure and $\vec{\Psi}$ is the viscous force vector:

$$
\vec{\psi}=-\frac{2}{3} \nabla[\eta(\nabla \cdot \vec{v})]+\eta\left[\nabla^{2} \vec{v}+\nabla(\nabla \cdot \vec{v})\right]+2(\nabla \eta \cdot \nabla) \vec{v}+\nabla \eta \times(\nabla \times \vec{v})
$$

The viscosity $\eta$ for a fully ionized plasma is given by ${ }^{37}$ :

$$
\eta=1.25 \times 10^{-19} \frac{5}{8 n^{i} A}\left(\frac{M m k_{D} T}{\pi}\right)^{1 / 2}\left(\frac{2 k_{B} T}{e^{2}}\right)^{2}
$$

where $M$ is the ion mass, $m$ is the electron mass, $e$ is the electron charge, $k_{B}$ is Boltzmann's constant, $n^{i}=1$ for a singly ionized plasma, and, for a fully ionized gas $(\alpha=1)$,

$$
A=2\left[\ln \left(1+\alpha^{2}\right)-\frac{\alpha^{2}}{1+\alpha^{2}}\right]=0.386
$$

The radial component of the momentum equation is used to solve for the radial velocity $v_{\tau}$ :

$$
\begin{aligned}
\rho\left(v_{r} \frac{\partial v_{\tau}}{\partial r}+v_{z} \frac{\partial v_{\tau}}{\partial z}-\frac{v_{\theta}^{2}}{r}\right) & =-\frac{\partial p}{\partial r}+\left(j_{\theta} B_{z}-j_{z} B_{\theta}\right)-v_{r}\left(\frac{4}{3} \frac{\eta}{r^{2}}+\frac{2}{3 r} \frac{\partial \eta}{\partial r}\right)+\frac{4}{3} \frac{\partial v_{\tau}}{\partial r}\left(\frac{\eta}{r}+\frac{\partial \eta}{\partial r}\right) \\
& +\frac{\partial v_{r}}{\partial z} \frac{\partial \eta}{\partial z}+\frac{4 \eta}{3} \frac{\partial^{2} v_{r}}{\partial r^{2}}+\eta \frac{\partial^{2} v_{r}}{\partial z^{2}}+\frac{\eta}{3} \frac{\partial^{2} v_{z}}{\partial r \partial z}+\frac{\partial \eta}{\partial z} \frac{\partial v_{z}}{\partial r}-\frac{2}{3} \frac{\partial \eta}{\partial r} \frac{\partial v_{z}}{\partial z}
\end{aligned}
$$

Equation (19) is recast in the form:

$$
\eta \frac{\partial^{2} v_{r}}{\partial r^{2}}+\Gamma_{r}^{1} \frac{\partial v_{r}}{\partial r}+\Gamma_{r}^{2} \frac{\partial v_{r}}{\partial z}-\Gamma_{r}^{3} v_{r}+\frac{3 \eta}{4} \frac{\partial^{2} v_{r}}{\partial z^{2}}=-S_{r}
$$

where

$$
\begin{aligned}
\Gamma_{r}^{1} & =\left(\frac{\eta}{r}+\frac{\partial \eta}{\partial r}-\frac{3 \rho v_{r}}{4}\right) \\
\Gamma_{r}^{2} & =\frac{3}{4}\left(\frac{\partial \eta}{\partial z}-\rho v_{z}\right) \\
\Gamma_{r}^{3} & =\left(\frac{\eta}{r^{2}}+\frac{1}{2 r} \frac{\partial \eta}{\partial r}\right)
\end{aligned}
$$


and

$$
S_{r}=\frac{3}{4}\left(-\frac{\partial p}{\partial r}+j_{\theta} B_{x}-j_{x} B_{\theta}+\frac{\eta}{3} \frac{\partial^{2} v_{z}}{\partial r \partial z}+\frac{\partial \eta}{\partial z} \frac{\partial v_{z}}{\partial r}-\frac{2}{3} \frac{\partial \eta}{\partial r} \frac{\partial v_{z}}{\partial z}+\frac{\rho v_{\theta}^{2}}{r}\right)
$$

The azimuthal component of the momentum equation is:

$$
\begin{aligned}
\rho\left(v_{r} \frac{\partial v_{\theta}}{\partial r}+v_{z} \frac{\partial v_{\theta}}{\partial z}+\frac{v_{r} v_{\theta}}{r}\right) & =j_{z} B_{r}-j_{r} B_{z}+\eta \frac{\partial^{2} v_{\theta}}{\partial r^{2}}+\eta \frac{\partial^{2} v_{\theta}}{\partial z^{2}}+\left(\frac{\eta}{r}+\frac{\partial \eta}{\partial r}\right) \frac{\partial v_{\theta}}{\partial r} \\
& +\frac{\partial \eta}{\partial z} \frac{\partial v_{\theta}}{\partial z}+v_{\theta}\left(-\frac{\eta}{r^{2}}-\frac{1}{r} \frac{\partial \eta}{\partial r}\right)
\end{aligned}
$$

which yields an equation for $v_{\theta}$ of the form:

$$
\eta \frac{\partial^{2} v_{\theta}}{\partial r^{2}}+\Gamma_{\theta}^{1} \frac{\partial v_{\theta}}{\partial r}+\Gamma_{\theta}^{2} \frac{\partial v_{\theta}}{\partial z}-\Gamma_{\theta}^{3} v_{\theta}+\eta \frac{\partial^{2} v_{\theta}}{\partial z^{2}}=-S_{\theta}
$$

where

$$
\begin{aligned}
& \Gamma_{\theta}^{1}=\left(\frac{\eta}{r}+\frac{\partial \eta}{\partial r}-\rho v_{r}\right) \\
& \Gamma_{\theta}^{2}=\left(\frac{\partial \eta}{\partial z}-\rho v_{z}\right) \\
& \Gamma_{\theta}^{3}=\left(\frac{\eta}{r^{2}}+\frac{1}{r} \frac{\partial \eta}{\partial r}+\frac{\rho v_{r}}{r}\right)
\end{aligned}
$$

and

$$
S_{\theta}=j_{z} B_{\tau}-j_{\tau} B_{z}
$$

Note that $\mathrm{B}_{\tau}=\mathrm{B}_{\mathbf{z}}=0$ in the self-field thruster, and no azimuthal velocity will be generated.

The axial component of momentum

$$
\begin{aligned}
\rho\left(v_{r} \frac{\partial v_{z}}{\partial r}+v_{s} \frac{\partial v_{z}}{\partial z}\right) & =-\frac{\partial p}{\partial z}+j_{r} B_{\theta}-j_{\theta} B_{r}+\eta \frac{\partial^{2} v_{z}}{\partial r^{2}}+\left(\frac{\eta}{r}+\frac{\partial \eta}{\partial r}\right) \frac{\partial v_{z}}{\partial r}+\frac{4}{3} \frac{\partial \eta}{\partial z} \frac{\partial v_{z}}{\partial z} \\
& +\frac{4 \eta}{3} \frac{\partial^{2} v_{z}}{\partial z^{2}}+\frac{\partial v_{r}}{\partial z}\left(\frac{\eta}{3 r}+\frac{\partial \eta}{\partial r}\right)-\frac{2}{3} \frac{\partial \eta}{\partial z}\left(\frac{v_{r}}{r}+\frac{\partial v_{r}}{\partial r}\right)+\frac{\eta}{3} \frac{\partial^{2} v_{r}}{\partial r \partial z}
\end{aligned}
$$

yields an equation for the axial velocity $v_{z}$ :

$$
\eta \frac{\partial^{2} v_{z}}{\partial r^{2}}+\Gamma_{z}^{1} \frac{\partial v_{z}}{\partial r}+\Gamma_{z}^{2} \frac{\partial v_{z}}{\partial z}+\frac{4 \eta}{3} \frac{\partial^{2} v_{z}}{\partial z^{2}}=-S_{z}
$$

where

$$
\begin{aligned}
& \Gamma_{z}^{1}=\left(\frac{\eta}{r}+\frac{\partial \eta}{\partial r}-\rho v_{r}\right) \\
& \Gamma_{z}^{2}=\left(\frac{4}{3} \frac{\partial \eta}{\partial z}-\rho v_{z}\right)
\end{aligned}
$$

and

$$
S_{z}=-\frac{\partial p}{\partial z}+j_{r} B_{\theta}-j_{\theta} B_{r}+\frac{\partial v_{r}}{\partial z}\left(\frac{\eta}{3 r}+\frac{\partial \eta}{\partial r}\right)-\frac{2}{3} \frac{\partial \eta}{\partial z}\left(\frac{v_{r}}{r}+\frac{\partial v_{r}}{\partial r}\right)+\frac{\eta}{3} \frac{\partial^{2} v_{r}}{\partial r \partial z}
$$


Energy. The conservation of energy, neglecting radiation losses, is given by:

$$
\rho(\vec{v} \cdot \nabla)\left(c_{p} T\right)=(\vec{v} \cdot \nabla) P+\nabla \cdot\left(\kappa_{T} \nabla T\right)+(\vec{E}+\vec{v} \times \vec{B}) \cdot \vec{j}+\phi_{v}
$$

where $c_{p}$ is the specific heat at constant pressure and $\kappa_{T}$ is the Spitzer-Harm thermal conductivity ${ }^{34}$ :

$$
\kappa_{T}=4.4 \times 10^{-10} \frac{T^{5 / 2}}{\ln \Lambda}
$$

The viscous dissipation $\Phi_{v}$ is $^{34,35}$ :

$$
\begin{array}{r}
\phi_{v}=\eta\left(2\left[\left(\frac{\partial v_{r}}{\partial r}\right)^{2}+\left(\frac{v_{r}}{r}\right)^{2}+\left(\frac{\partial v_{z}}{\partial z}\right)^{2}\right]+\left(\frac{\partial v_{\theta}}{\partial z}\right)^{2}+\left(\frac{\partial v_{r}}{\partial z}+\frac{\partial v_{z}}{\partial r}\right)^{2}+\left(\frac{\partial v_{\theta}}{\partial r}-\frac{v_{\theta}}{r}\right)^{2}\right) \\
+\lambda\left(\frac{\partial v_{r}}{\partial r}+\frac{v_{r}}{r}+\frac{\partial v_{z}}{\partial z}\right)^{2}
\end{array}
$$

where $\lambda$ represents the second coefficient of viscosity for a monatomic gas:

$$
\lambda+\frac{2}{3} \eta=0
$$

The energy equation is rewritten in the form:

$$
\kappa_{T} \frac{\partial^{2} T}{\partial r^{2}}+\Gamma_{T}^{1} \frac{\partial T}{\partial r}+\Gamma_{T}^{2} \frac{\partial T}{\partial z}+\kappa_{T} \frac{\partial^{2} T}{\partial z^{2}}=-S_{T}
$$

where

$$
\begin{aligned}
& \Gamma_{T}^{1}=\left(\frac{\kappa_{T}}{r}+\frac{\partial \kappa_{T}}{\partial r}-\rho c_{p} v_{\tau}\right) \\
& \Gamma_{T}^{2}=\left(\frac{\partial \kappa_{T}}{\partial z}-\rho c_{p} v_{z}\right)
\end{aligned}
$$

and

$$
S_{T}=(\vec{v} \cdot \nabla) P+(\vec{E}+\vec{v} \times \vec{B}) \cdot \vec{j}+\phi_{v}
$$

which is then solved for the single-fluid plasma temperature.

The set of fluid equations are closed with an ideal gas equation of state relating the plasma pressure, density, and temperature:

$$
p=\rho R T
$$

\section{IIc. Finite Difference Formulation}

The governing equations presented above have the general form:

$$
f=\alpha_{1} \frac{\partial^{2} Y}{\partial r^{2}}+\alpha_{2} \frac{\partial Y}{\partial r}+\alpha_{3} \frac{\partial Y}{\partial z}+\alpha_{4} \frac{\partial^{2} Y}{\partial z^{2}}+\alpha_{0} Y+S
$$

where the $\alpha_{n}$ denote nonconstant coefficients and $S$ represents a possible source term. The coupled form of the equations hinders an analytic solution, and suggests the use of an iterative numerical approach. The equations are written in finite difference form, and solved on a uniform rectangular grid using a generalized 
Newton-Raphson iteration method ${ }^{38}$. Second derivatives are represented by a second-order central difference formulation:

$$
\begin{aligned}
& \frac{\partial^{2} Y}{\partial r^{2}}=\frac{Y(j, i+1)-2 Y(j, i)+Y(j, i-1)}{(\Delta r)^{2}} \\
& \frac{\partial^{2} Y}{\partial z^{2}}=\frac{Y(j+1, i)-2 Y(j, i)+Y(j-1, i)}{(\Delta z)^{2}}
\end{aligned}
$$

where the index $j$ represents nodal points along the axial grid direction, $i$ represents nodal points along the radial grid direction, and $\Delta r$ and $\Delta z$ are the radial and axial grid spacings, respectively. First derivatives are written using a first-order switching scheme, which is based upon the sign of the coefficients multiplying the derivatives ${ }^{38}$ :

$$
\begin{aligned}
& \frac{\partial Y}{\partial r}= \begin{cases}\frac{Y(j, i+1)-Y(j, i)}{\Delta r} & \alpha_{2} \geq 0 \\
\frac{Y(j, i)-Y(j, i-1)}{\Delta r} & \alpha_{2}<0\end{cases} \\
& \frac{\partial Y}{\partial z}= \begin{cases}\frac{Y(j+1, i)-Y(j, i)}{\Delta z} & \alpha_{3} \geq 0 \\
\frac{Y(j, i)-Y(j-1, i)}{\Delta z} & \alpha_{3}<0\end{cases}
\end{aligned}
$$

This scheme preserves the dominance of the $Y(j, i)$ term and assures stability of the numerical solution. The first-order continuity equation (15) is solved for $\xi$ using an automatic upwind/downwind differencing method:

$$
\begin{aligned}
& \frac{\partial \xi v_{r}}{\partial r}=\frac{1}{2 \Delta r}\left[\left(u_{f}-\left|u_{f}\right|\right) \xi(j, i+1)+\left(u_{f}+\left|u_{f}\right|\right) \xi(j, i)+\left(-u_{b}+\left|u_{b}\right|\right) \xi(j, i)-\left(u_{b}+\left|u_{b}\right|\right) \xi(j, i-1)\right] \\
& \frac{\partial \xi v_{z}}{\partial z}=\frac{1}{2 \Delta z}\left[\left(v_{f}-\left|u_{f}\right|\right) \xi(j+1, i)+\left(v_{f}+\left|v_{f}\right|\right) \xi(j, i)+\left(-v_{b}+\left|v_{b}\right|\right) \xi(j, i)-\left(v_{b}+\left|v_{b}\right|\right) \xi(j-1, i)\right]
\end{aligned}
$$

where

$$
\begin{aligned}
u_{f} & =\frac{1}{2}\left(v_{r}(j, i+1)+v_{r}(j, i)\right) \\
u_{b} & =\frac{1}{2}\left(v_{r}(j, i)+v_{r}(j, i-1)\right) \\
v_{f} & =\frac{1}{2}\left(v_{z}(j+1, i)+v_{z}(j, i)\right) \\
v_{b} & =\frac{1}{2}\left(v_{r}(j, i)+v_{\tau}(j-1, i)\right)
\end{aligned}
$$

This method allows the continuity equation to be kept in conservative form while retaining numerical stability.

Once written in their finite difference analogs, each equation is regrouped into the general form:

$$
F=a_{0} Y(j, i)+a_{1} Y(j, i+1)+a_{2} Y(j, i-1)+a_{3} Y(j+1, i)+a_{4} Y(j-1, i)+S(j, i)
$$

where the $a_{n}$ are nonconstant coefficients, which must be evaluated at each grid location. The generalized Newton-Raphson iteration method

$$
Y(j, i)=Y(j, i)-\omega \frac{F}{[\partial F / \partial Y(j, i)]}
$$


is then used to iteratively solve each finite difference equation. An over-relaxation factor $\omega$ is used to speed convergence; its value lies between 1 and 2, and was determined through trial and error for each equation being solved.

Program execution is presented schematically in Figure 2. The fixed grid is divided into 50 radial by 100 axial nodes, and each equation is iterated first in the axial and then in the radial direction until a relative convergence criteria is satisfied (typically to within a tolerance of $10^{-4}$ ). The process is repeated for each equation in turn, and the entire loop through the full set of equations is repeated until the exhaust velocity and plasma potential have each converged to within $1 \%$ of their previous loop values.

Mass flow conservation is checked by numerically integrating $\rho v_{z}$ radially along the thruster inlet and again at the thruster exit plane. Mass flow rates at the exit plane were initially found to be off by $15-20 \%$, a consequence of the finite difference formulation employed; similar results have been reported for the Stuttgart finite difference MPD $\operatorname{codes}^{28,30}$. In an attempt to improve mass flow conservation, a weighting scheme was incorporated into the finite difference solution of the continuity equation. Equations (43) were replaced by:

$$
\begin{aligned}
& u_{f}=\left(v_{r}(j, i+1)+v_{r}(j, i) \tilde{w}\right) /(1+\tilde{w}) \\
& u_{b}=\left(v_{r}(j, i)+v_{r}(j, i-1) \tilde{w}\right) /(1+\tilde{w}) \\
& v_{f}=\left(v_{z}(j+1, i)+v_{z}(j, i) \tilde{w}\right) /(1+\tilde{w}) \\
& v_{b}=\left(v_{r}(j, i)+v_{r}(j-1, i) \tilde{w}\right) /(1+\tilde{w})
\end{aligned}
$$

where $\tilde{w}$ is a weighting factor, initially set to unity. After each loop through the continuity equation, the ratio $\Re$ of the mass flow at the thruster inlet plane to the mass flow at the exit plane was calculated and the weighting factor modified according to:

$$
\bar{w}=\Re \tilde{w}
$$

The continuity equation was then reiterated until the mass flow ratio $\Re=1 \pm 0.01$. Although the value of the weighting factor changes over each loop, the actual velocities are not altered and the calculated mass flow rates can be brought into close agreement.

Thrust and Specific Impulse. The electromagnetic thrust $F_{\text {em }}$ is calculated by numerically integrating the axial $\vec{j} \times \vec{B}$ body force over the current carrying volume, including regions downstream of the thruster exit:

$$
F_{e m}=\int_{V}(\vec{j} \times \vec{B})_{x} d V
$$

Additional pressure forces are numerically integrated over the inner surfaces of the thrust chamber, and combined with the electromagnetic thrust calculation to provide total thrust. A second total thrust calculation is then performed using:

$$
F=\dot{m} v_{e x}+\int_{V_{\text {out }}}(\vec{j} \times \vec{B})_{2} d V_{\text {out }}+\left(p_{e}-p_{g}\right) A_{e}
$$

The exhaust velocity $v_{e x}$ is given by:

$$
v_{e x}=\frac{\sum_{i} \rho(j a, i) v_{z}(j a, i)}{\sum_{i} \rho(j a, i)}
$$

where the axial index $j a$ denotes the anode exit plane and the radial integration extends from the thruster centerline to the inner anode radius. The integration of the electromagnetic body force is performed over the current carrying volume external to the thruster. The pressure force term corresponds to an imbalance between the pressure at the anode exit plane and the background gas pressure, evaluated over the thruster 
exit area $A_{\varepsilon}$. The complementary thrust calculation methods provide an independent check on the total thrust, and allow estimates to be made of the various thrust components.

\section{IId. Starting Values and Boundary Conditions}

Primary input into the code consists of the discharge current, propellant ion mass (amu), and propellant mass flow rate. Secondary input defines code options, such as maximum bulk electrode temperatures, background gas pressures, and initial estimates for the plasma transport coefficients. Bulk electrode temperatures are typically set at $3000 \mathrm{~K}$, and electrode surface temperatures are then evaluated by averaging the temperature immediately above the electrode surface with the bulk electrode temperature, providing a smoother temperature transition between the electrode surface and the hot plasma. Background gas pressures are set between $1.3 \times 10^{-2}$ and $1.3 \times 10^{-4} \mathrm{~Pa}\left(10^{-4}\right.$ and $10^{-6}$ torr, respectively). No appreciable difference is found in calculated thruster performance using either background pressure value.

The inlet velocity $v_{0}$ is assumed to be sonic and uniform at the backplate. The inlet density $\rho_{0}$ is assumed to be uniform and is calculated from the $1-\mathrm{D}$ continuity equation, $\dot{m}=\rho_{0} v_{0} A_{0}$, where $A_{0}$ is the exposed backplate surface area. Radial and azimuthal velocities are initially set to zero, and are defined by symmetry to remain zero along the centerline. Initial temperatures throughout the calculation region are set to the bulk electrode temperatures. Initial velocities and densities in the calculation region are set to their values at the backplate. A no-slip velocity condition is employed at all insulator and electrode surfaces.

Electric fields at insulator surfaces are set equal to zero. Electric fields which enter perpendicular to electrode surfaces satisfy the condition $\partial \vec{E}_{n} / \partial \hat{n}=0$, where $\hat{n}$ denotes a unit vector normal to the surface. Electric fields lying along electrode surfaces are set to zero, consistent with the electrodes being equipotential surfaces. The magnetic stream line $\psi$ is set equal to $-\mu_{0} J /(2 \pi)$ along the backplate, zero along the centerline, and is assumed to be continuous at both the outer radial grid boundary and and downstream axial grid boundary. Setting $\psi=0$ at the thruster exit plane prevents current from blowing out of the thruster, while setting $\psi=0$ at the downstream grid boundary artificially compresses the current blown downstream.

\section{IIe. Stability and Performance}

Steep radial pressure gradients, typically caused by a combination of high densities and sharp temperature gradients near the cathode tip, may cause the code to become unstable. Negative radial pressure gradients near the plume centerline can drive the radial velocity positive, causing the centerline density to plummet and the local Hall parameter to skyrocket. This effect can propagate into the field equations, precipitating numerical instabilities from which the steady-state code cannot recover. This problem is currently handled by under-relaxing the pressure gradient terms during the first several iterations, allowing the flow and discharge pattern to stabilize before the pressure gradient terms are brought up to their full values. A more elegant solution, currently under investigation, is to use nonuniform or multigrid algorithms to refine the computational mesh near the electrode surfaces, allowing the sharp gradients to be handled more effectively.

To shorten loop convergence times, the temperature and velocity components are averaged with their previous loop values. This damps out minor fluctuations as a solution is approached, allowing more rapid loop convergence. Tests performed with and without smoothing yield identical results. Model convergence with smoothing is typically obtained within 10-12 loops through the equations, requiring approximately $45 \mathrm{CPU}$ minutes on a VAX- 9000 computer. The code has not yet been optimized for a CRAY computing system.

\section{Comparison with Experiment}

The self-field model was compared with published experimental results for the University of Stuttgart coaxial ZT-1 MPD thruster ${ }^{39}$ and for the Princeton University half-scale flared anode thruster (HSFAT) (t) $^{\text {th }}$. The ZT- 
1 thruster anode is segmented, allowing anode current distributions to be evaluated during steady state operation. In addition, the thruster has been numerically modeled by Sleziona et al. ${ }^{28}$, allowing direct comparisons between the Stuttgart and NASA LeRC codes. The HSFAT was chosen to test the accuracy with which a fixed numerical grid can model a flared thruster geometry, while the extensive experimental data which exists for the $\mathrm{HSFAT}^{40,41}$ provides an excellent opportunity to exercise the code over a wide range of currents and mass flow rates.

\section{IIIa. ZT-1 Thruster Comparisons}

The University of Stuttgart ZT-1 MPD thruster is a cylindrical, steady-state, water-cooled research device with a $2 \%$ thoriated tungsten cathode and a segmented copper anode (Figure $3 \mathrm{a}$ ). The two segments closest to the backplate are electrically isolated, with the remaining three rings connected to form the anode. The backplate is made of copper, and is electrically isolated from the electrodes. Propellant gas may be introduced through a backplate annulus surrounding either the cathode or the anode, or the flow may be split and sent through both injector rings. The anode inner diameter is $7.0 \mathrm{~cm}$ and has a total length of $15 \mathrm{~cm}$, including the insulated anode segments. The cathode is $1.8 \mathrm{~cm}$ in diameter, and for the comparison below has an exposed length of $15 \mathrm{~cm}$ within the thrust chamber.

To provide comparison data for the Stuttgart code, the ZT-1 thruster was operated at a discharge current of $6000 \mathrm{~A}$, with an argon propellant mass flow rate of $6 \mathrm{~g} / \mathrm{s}$ split $2: 4$ between anode and cathode ${ }^{28}$. Current distribution was measured in the three conducting anode segments, along with the total discharge voltage. The engine has not yet been mounted on a thrust stand, so no direct thrust measurements were available for comparison. Results of the Stuttgart model show excellent agreement with the current distribution along the anode, while the calculated discharge voltage, neglecting electrode fall potentials, is only slightly under the measured total voltage. The experimental and calculated values are summarized in Table 1, with predicted current contours displayed in Figure $3 \mathrm{~b}$. The thruster was operated steady-state, hence no direct current contour measurements could be performed. A similar thruster, designated ZP-1, was constructed to operate in a quasi-steady mode ${ }^{39}$; comparisons between the measured current distributions and calculated current distributions were quite poor, however, and were ascribed to variations in the cathode emission distributions between quasi-steady and steady-state operation ${ }^{30,39}$. Unfortunately, the reported comparisons were at different discharge currents and mass flow rates (although similar $J^{2} / \dot{m}$ ), causing some ambiguity in their conclusions.

\begin{tabular}{|c|c|c|c|}
\hline \multirow{4}{*}{$\begin{array}{c}\text { ZT-1 THRUSTER } \\
\text { ANODE SEGMENT \# }\end{array}$} & \multicolumn{2}{|c|}{ U. STUTTGART } & \multirow{2}{*}{$\begin{array}{l}\text { NASA LERC } \\
\text { MODEL }\end{array}$} \\
\hline & EXPERIMENT & MODEL & \\
\hline & \multicolumn{3}{|c|}{ ANODE CURRENT FRACTION } \\
\hline & 0.46 & 0.44 & 0.47 \\
\hline 2 & 0.27 & 0.27 & 0.23 \\
\hline 3 & 0.27 & 0.29 & 0.30 \\
\hline & \multicolumn{3}{|c|}{ DISCHARGE VOLTAGE (V) } \\
\hline VOLTAGE (V) & $19 \mathrm{~V}$ & $14 \mathrm{~V}$ & $3.7 \mathrm{~V}$ \\
\hline
\end{tabular}

Table 1: Current distribution and discharge voltage comparisons for the ZT-1 MPD thruster operating at $6000 \mathrm{~A}, 6 \mathrm{~g} / \mathrm{s}$. Calculated voltages do not include electrode fall potentials.

Results of the NASA LeRC simulation of the ZT-1 thruster are also shown in Table 1, and indicate fair agreement with both the experimental and numerical Stuttgart results. The steady-state LeRC code predicts slightly higher current concentrations along the upstream and downstream anode sections, and a lower current concentration along the central anode section. The calculated enclosed current contours are displayed in Figure 3c, and compare favorably with the calculated Stuttgart results. The different downstream 
attachments shown in Figures $3 b$ and $3 c$ are a result of the boundary conditions used on the anode face. The Stuttgart model assumes a partially insulated anode face, which forces the current to reattach near the anode lip. In Figure 3c, the anode face is left uninsulated, and the downstream current does not appear to reattach within the simulated region.

The plasma potential calculated with the LeRC code is substantially lower than the total measured voltage, reaching only 3.7 volts, or roughly $20 \%$ of the discharge voltage. The plasma drop, calculated by radially integrating Equation 7a from cathode to anode, does not include the electrode fall voltages or any plasma ionization penalties; however, neither does the Stuttgart calculation, which comes remarkably close to matching the full discharge voltage. The reason for this discrepancy lies in the different expressions used for the electrical conductivity. The average electrical conductivity calculated by the Stuttgart code is ${ }^{29} 2000-2500$ $\mathrm{mho} / \mathrm{m}$ within the thruster, while the average value calculated in the NASA LeRC model is approximately $6000 \mathrm{mho} / \mathrm{m}$ within the thruster. The calculated plasma potential is inversely proportional to the conductivity (Equation 7a), which results in the higher potential calculated by the Stuttgart model. Resolving this issue will require better approximations for the plasma transport coefficients, as well as a sheath model to accurately calculate electrode fall contributions to the total voltage drop.

Calculated thrust values were not reported for the ZT-1 thruster under the assumed operating conditions. A thrust of approximately $28 \mathrm{~N}$, including $14 \mathrm{~N}$ of electromagnetic thrust, was calculated by the Stuttgart code $^{28}$ for the ZT- 1 thruster using a discharge current of $10 \mathrm{kA}$ and an argon mass flow rate of $6 \mathrm{~g} / \mathrm{s}$. The LeRC code was operated with these same parameters to verify the thrust calculation routine. The total calculated thrust was $27 \mathrm{~N}$, with $13 \mathrm{~N}$ of electromagnetic thrust, in good agreement with the Stuttgart predictions. For the ZT-1 thruster operating at a discharge current of $6 \mathrm{kA}$, the LeRC code calculated a total thrust of approximately $11 \mathrm{~N}$, with $4.7 \mathrm{~N}$ of electromagnetic thrust. The corresponding specific impulse is approximately $185 \mathrm{~s}$. Using the measured discharge voltage of 19 volts at $6000 \mathrm{~A}$ and the calculated thrust of $11 \mathrm{~N}$, the estimated efficiency of the ZT-1 thruster under the given operating conditions is approximately $9 \%$.

Temperature, pressure, and density contours calculated with the NASA LeRC code are displayed for the ZT-1 thruster in Figures 4(a) through 4(c). The pressure and density contours are normalized to their average inlet values and plotted as $\log _{10}\left[\mathrm{P} / \mathrm{P}_{0}\right]$ and $\log _{10}\left[\rho / \rho_{0}\right]$, respectively, to bring out details in the exhaust plume. Electric equipotentials are plotted in Figure $4 \mathrm{~d}$, showing equipotential line convergence at the interface between the insulating and conducting anode segments, and at the inlet where the cathode penetrates the insulating backplate. Local Mach number contours are displayed in Figure 4e, and the velocity flow field is shown in Figure 4f. Of particular interest is the high temperature interelectrode region shown in Figure $4 a$; a similar temperature increase was observed in the Stuttgart modeling results ${ }^{28,29}$. The convergence of equipotential lines along the junction of the insulated and conducting anode segments indicates a region of strong electric fields, and a plausible explanation for the increased temperature is localized Joule heating (cf Equation 31). To test this hypothesis, a second numerical run was performed for the ZT-1 thruster using identical operating conditions, but with the insulated segments replaced by conducting anode segments. Results are shown in Figures $5 \mathrm{a}$ through $5 \mathrm{f}$, with the enclosed current contours displayed in Figure $5 \mathrm{~g}$. The high temperature interelectrode region appears in nearly the same location with approximately the same temperature as in the ZT-1 thruster with insulating segments. The high temperature region is thus not a result of localized Joule heating near the insulator/electrode interface, but is generic to the ZT-1 thruster geometry under the assumed operating conditions. Further modeling would be useful to determine how different mass flow rates and discharge currents affect the interelectrode temperature distribution, and whether the localized increase in temperature can be reduced by changing the anode radius or the thruster length. A combination of experiment and simulation could determine the effect of the high temperature anomaly on electrode erosion, and produce design modifications which may mitigate the severe upstream cathode erosion observed in the ZT- 1 thruster ${ }^{42}$.

Temperatures are also observed to increase in the flow exhaust region, with maximum temperatures occuring 
downstream of the thruster exit plane. The corresponding pressure distributions (Figures $4 \mathrm{~b}$ and $5 \mathrm{~b}$ ) show increased pressures at locations of increased temperature, both within the chamber and downstream of the cathode tip. The pressure distribution for the ZT-1 thruster with insulating segments is somewhat more complex than the ZT-1 without insulators, indicating a pressure rise slightly upstream of the anode exit plane compared with a relatively smooth pressure transition in the ZT-1 without insulators. Mach number contours (Figures $4 \mathrm{e}$ and 5e) show the flow is more smoothly accelerated in the ZT-1 without insulators, although some flow deceleration occurs in the high pressure interelectrode region for both cases. Smoother flow is also shown in the velocity vector diagrams (Figures $4 \mathrm{f}$ and $5 \mathrm{f}$ ), which display an interesting difference in the exhaust velocity profiles for the two cases. Calculated thrust values were $11.1 \mathrm{~N}$ for each case, including $4.7 \mathrm{~N}$ of electromagnetic thrust.

The ZT- 1 thruster comparisons allow the self-field model to be tested against experimental and independent numerical results, and provide some confidence that the code can accurately predict major aspects of steadystate MPD thruster performance. However, the disparity in predicted plasma voltages underscores the need for accurate electrode sheath models and improved expressions for the plasma transport coefficients in calculating total discharge voltages. The prediction of a high temperature region occuring within the ZT-1 thruster channel, and the possible correlation of this region with a measured increase in cathode erosion, reiterate the need for a balanced experimental and numerical approach in evaluating MPD thruster dynamics.

\section{IIIb. HSFAT Thruster Comparisons}

The half-scale flared anode thruster is depicted schematically in Figure 6. Vacuum tank constraints limit thruster operation to pulsed, quasi-steady operation, and the continuous copper anode is not actively cooled. The $0.5 \mathrm{~cm}$ diameter cathode is made of $2 \%$ thoriated tungsten, and extends the full $10 \mathrm{~cm}$ length of the anode. The anode inner radius is approximately $1.6 \mathrm{~cm}$ at the backplate, extending $1.4 \mathrm{~cm}$ downstream before beginning a $12.5^{\circ}$ half-angle flare. The flared section continues for roughly $4 \mathrm{~cm}$, followed by a 4.6 $\mathrm{cm}$ straight channel section. Propellant is injected through an insulating boron nitride backplate, with half the propellant mass flow injected through an annulus at the cathode base, and the remaining half injected through a ring of 12 evenly spaced ports radially located at $1.5 \mathrm{~cm}$. Argon propellant was used in all tests, with mass flow rates of $0.75,1.5$, and $3 \mathrm{~g} / \mathrm{s}$ and discharge currents up to $23 \mathrm{kA}$ at the higher mass flow rate. Voltage-current characteristics were adequately described by the relation:

$$
V=2.05 \times 10^{-3} J+1.5 \times 10^{-14} \frac{J^{3}}{\dot{m}}+30
$$

where $V$ is the total discharge voltage in volts, $J$ is the discharge current in amps, and $\dot{m}$ is the propellant mass flow rate expressed in $\mathrm{kg} / \mathrm{s}$. The onset of operational instability, defined as a $10 \%$ hash in the otherwise uniform voltage signal, was noted to occur at a critical $J^{2} / \dot{m}$ value of approximately $1.8 \times 10^{11} \mathrm{~A}^{2}-\mathrm{s} / \mathrm{kg}$.

Table 2 presents a matrix of the modeled $J^{2} / \dot{m}$ values as a function of mass flow rate and total discharge current. Model comparisons were performed for each of the given mass flow rates at $J^{2} / \dot{\mathrm{m}}$ values of approximately $2.5 \times 10^{10}, 5.0 \times 10^{10}, 1.05 \times 10^{11}$, and $1.5 \times 10^{11} \mathrm{~A}^{2}-\mathrm{s} / \mathrm{kg}$. Additional calculations were performed at 3 $\mathrm{g} / \mathrm{s}, J^{2} / \dot{m}=6.1 \times 10^{9} \mathrm{~A}^{2}-\mathrm{s} / \mathrm{kg}$, and $1.5 \mathrm{~g} / \mathrm{s}, J^{2} / \dot{m}=2.1 \times 10^{11} \mathrm{~A}^{2}-\mathrm{s} / \mathrm{kg}$, to extend the range of comparisons.

Thrust. Figure 7 presents measured and predicted thrust for the BSFAT as a function of current. The code accurately models the observed thrust for each of the mass flow rates and discharge currents up to $J^{2} / \dot{m}$ values of approximately $1.5 \times 10^{11} \mathrm{~A}^{2}-\mathrm{s} / \mathrm{kg}$, at which point the calculated thrust begins to deviate from the observed values. As noted previously, the experimentally determined value at which $10 \%$ voltage oscillations occur is approximately $1.8 \times 10^{11} \mathrm{~A}^{2}-\mathrm{s} / \mathrm{kg}$, and it is probable that the simple single-fluid MHD code cannot accurately model the physical processes occuring in the thruster as operational instability is approached. It is interesting to note that the observed thrust at the $3 \mathrm{~g} / \mathrm{s}$ mass flow rate displays a cubic dependence on the current above $1.8 \times 10^{4} \mathrm{~A}$, a trend which is missed by the code. These effects are a valuable aid in defining regimes of model accuracy, and provide essential benchmarks against which numerical simulations must be 


\begin{tabular}{|c|c|c|c|c|c|c|c|c|c|}
\hline \hline HSFAT & \multicolumn{7}{|c|}{ DISCHARGE CURRENT $\left(\times 10^{3} \mathrm{~A}\right)$} \\
MASS FLOW & $\mathbf{4 . 3}$ & $\mathbf{6 . 1}$ & $\mathbf{8 . 7}$ & $\mathbf{1 0 . 6}$ & $\mathbf{1 2 . 4}$ & $\mathbf{1 5 . 0}$ & $\mathbf{1 7 . 8}$ & $\mathbf{2 1 . 3}$ \\
\cline { 2 - 8 } RATE (kg/s) & \multicolumn{7}{|c|}{$\mathrm{J}^{2} / \dot{m} \times 10^{9} \mathbf{A}^{2}-\mathbf{s} / \mathbf{k g}$} \\
\hline $3 \times 10^{-3}$ & 6.1 & - & 25 & - & 51 & - & 105 & 150 \\
$1.5 \times 10^{-3}$ & - & 25 & 50 & - & 103 & 150 & 212 & - \\
$7.5 \times 10^{-4}$ & 25 & 50 & 103 & 150 & - & - & - & - \\
\hline \hline
\end{tabular}

Table 2: Values of mass flow rate $(\dot{m})$, discharge current $(J)$, and $J^{2} / \dot{m}\left(\times 10^{9} \mathrm{~A}^{2}-\mathrm{s} / \mathrm{kg}\right)$ used in the HSFAT comparisons.

tested and refined.

Figure 8 displays the calculated electromagnetic thrust and the calculated total thrust plotted against $J^{2} / \dot{m}$ for each of the propellant mass flow rates. The electromagnetic thrust contribution increases with increasing $J^{2} / \dot{m}$, and dominates the acceleration at $J^{2} / \dot{m}$ values above $8-10 \times 10^{10} \mathrm{~A}^{2}-\mathrm{s} / \mathrm{kg}$. At the highest $J^{2} / \dot{m}$ value, the electromagnetic thrust calculated with Equation 48 is actually $2-5 \%$ higher than the total thrust calculated using Equation 49. Gilland ${ }^{41}$ reports that higher thrust values were obtained for the HSFAT using electromagnetic probe results versus actual thrust measurements, and accounts for this difference by incorporating viscous drag effects. While it is tempting to invoke this effect for the differences shown in Figure 8, the independent total thrust calculations discussed in Section II are also off by similar amounts, indicating the discrepancies which appear in Figure 8 are more likely due to numerical inaccuracies rather than actual physical effects. This result points out an additional area in the model which needs improvement, and reiterates the need for independent checks to verify model predictions.

Thrust Coefficients. The thrust for self-field MPD thrusters may be expressed ${ }^{43}$ :

$$
T=b J^{2}
$$

where $b$ is the thrust coefficient, defined as:

$$
b=\frac{\mu_{0}}{4 \pi}\left(\ln \frac{r_{a}}{r_{c}}+\delta\right)
$$

and $\delta$ may vary between $1 / 4$ and $3 / 4$, depending upon where the current attaches to the cathode. Equation (52) provides a fairly accurate estimate of the electromagnetic thrust for coaxial MPD thrusters where $b$ is well defined, but is inaccurate for flared thruster geometries and is unreliable when the thrust has a large electrothermal component. Figure 9 reproduces experimentally determined values of the thrust coefficient for the HSFAT as a function of $J^{2} / \dot{m}$, with model predictions overlayed on the experimental data. The code is able to accurately predict the thrust coefficient over the full range of $J^{2} / \dot{m}$ values. Figure 10 plots the thrust coefficient versus current to bring out the dependence on mass flow; again, there is good agreement between measured and predicted values for all mass flow rates. As reported by Gilland ${ }^{40,41}$, the thrust coefficient approaches a value of $1.1-1.2 \times 10^{-7} \mathrm{~N} / \mathrm{A}^{2}$ as the electromagnetic thrust component begins to dominate the flow. Figure 11 displays the thrust coefficient versus $J^{2} / \dot{m}$ using only the predicted electromagnetic component of thrust, plotted together with the thrust coefficients calculated using the total thrust. The electromagnetic thrust coefficients remain fairly constant at a value of approximately $1.1-1.2 \times 10^{-7} \mathrm{~N} / \mathrm{A}^{2}$, indicating that the higher thrust coefficients observed at lower $J^{2} / \dot{m}$ values are due primarily to large electrothermal thrust contributions rather than current redistribution along the flared anode or cathode surfaces.

Viscous Losses. Figure 12 plots the ratio of calculated viscous drag to calculated total thrust as a function of $\mathrm{J}^{2} / \dot{\mathrm{m}}$. The viscous drag ratio increases with increasing $J^{2} / \dot{\mathrm{m}}$ and decreasing mass flow rate, in qualitative 
agreement with the scaling arguments of Wolff ${ }^{44}$. At a mass flow rate of $3 \mathrm{~g} / \mathrm{s}$, the viscous drag ratio increases from just over $1 \%$ of the total thrust at $J^{2} / \dot{m}=2.5 \times 10^{10} \mathrm{~A}^{2}-\mathrm{s} / \mathrm{kg}$ to roughly $3.5 \%$ of the total thrust at $1.5 \times 10^{11} \mathrm{~A}^{2}-\mathrm{s} / \mathrm{kg}$. At the lower mass flow rate of $0.75 \mathrm{~g} / \mathrm{s}$, the viscous drag ratio rises from just over $2 \%$ of the total thrust at $2.5 \times 10^{10} \mathrm{~A}^{2}-\mathrm{s} / \mathrm{kg}$ to over $6 \%$ of the total thrust at $1.5 \times 10^{11} \mathrm{~A}^{2}-\mathrm{s} / \mathrm{kg}$. These results indicate that some benefit in performance might be derived by operating at higher mass flow rates for a given $J^{2} / \dot{m}$.

Enclosed Current Contours. The enclosed current contours measured by Gilland ${ }^{40,41}$ for the quasi-steady HSFAT are presented in Figure 13, for discharge currents of $7.9 \mathrm{kA}$ and $17.8 \mathrm{kA}$ and a mass flow rate of $3 \mathrm{~g} / \mathrm{s}$. At $7.9 \mathrm{kA}$, roughly $80 \%$ of the current attaches along the straight anode section downstream of the anode flare, with $60 \%$ congregating along the last $2 \mathrm{~cm}$ of the anode. At the higher discharge current, nearly $40 \%$ of the current remains in the straight anode channel near the backplate, with the remaining $60 \%$ spread along the anode downstream of the flared section. For comparison, the calculated enclosed current contours are presented as a matrix of mass flow rates and $J^{2} / \dot{m}$ values in Figure 14 . There is little resemblance between the measured quasi-steady current distributions and the calculated steady-state current distributions. As discussed in Section IIIa, similar differences were reported by Sleziona et a $f^{28,30}$ when they compared calculated steady-state ZT-1 thruster current distributions with quasi-steady ZP-1 thruster current distributions measured under different operating conditions but similar $J^{2} / \dot{m}$. They argue that the current preferentially attaches near the cathode base in pulsed, quasi-steady thrusters, and is more evenly distributed along the hot cathode during steady-state thruster operation; consequently, the current distributions are not expected to be comparable. The use of different operating conditions tends to weaken this argument; however, both the Stuttgart code and the LeRC code predict significantly different steady-state current distributions than those actually observed in quasi-steady thruster operation, while accurately simulating anode current distributions in steady-state segmented anode thrusters. This raises the issue of whether quasi-steady current distribution measurements accurately represent steady-state current distributions, and the equally valid issue of whether numerical models which ignore electrode processes can accurately simulate current distributions within the thruster.

The ability of the steady-state code to predict the quasi-steady HSFAT thrust and thrust coefficient values under a variety of operating conditions indicates that the current distribution is less important than the total discharge current when calculating these global thruster parameters, and either quasi-steady or steady-state experimental data may be used to verify such predictions. The results of the ZT-1 thruster modeling with and without insulating segments, however, indicates that the current distribution does affect the development of the plasma flow properties (temperature, pressure, etc.), and underscores the need to determine whether quasi-steady thruster measurements are truly representative of steady-state thruster operation. An experimental comparison of anode current distributions and plasma plume properties for a single, segmented anode thruster operated under pulsed and steady-state conditions should be performed to expand upon the results of the Stuttgart ZT-1/ZP-1 current distribution experiments, and to determine the extent to which plasma flow conditions might vary between quasi-steady and steady-state operation. In addition, electrode processes must be coupled into the numerical model to evaluate the effect of sheaths on electrode current attachment. Little confidence can be placed in detailed comparisons between quasi-steady plasma flow measurements and numerical steady-state flow predictions until these issues are resolved.

While thrust chamber predictions must await validation, useful trends can be established to provide insight into steady-state thruster operation. Figure 14 shows the predicted steady-state enclosed current contours for the HSFAT for a variety of mass flow rates and $J^{2} / \dot{m}$ values. The average magnetic Reynolds number for each case, defined by:

$$
R_{M}=\mu_{10} \bar{\sigma} v_{e x} L
$$

where $\bar{\sigma}$ is the average electrical conductivity, $v_{e \cdot \text { is }}$ is the exhaust velocity, and $L$ is a length parameter, taken to be the difference between the anode and cathode radius, is displayed under each figure. Typically 
$40-50 \%$ of the current is contained within the upstream straight channel section of the thruster for all cases considered. For a given mass flow rate, a larger fraction of the discharge current is blown downstream of the anode exit plane as $\mathrm{J}^{2} / \dot{\mathrm{m}}$ is increased. This result is commensurate with the increasing value of the magnetic Reynolds number, which is a measure of the ratio of magnetic convection to magnetic diffusion; as $R_{M}$ increases, more of the magnetic field is convected with the plasma flow. This effect is observed in Figure 14 , where the enclosed current contours are equivalent to induced magnetic field streamlines (cf Section Ila). For a given $J^{2} / \dot{m}$, the magnetic Reynolds number decreases with decreasing mass flow rate, and the current is pulled back into the thruster.

Figure 15 displays the fraction of electromagnetic thrust generated by current blown downstream of the anode exit plane for the HSFAT under the assumed steady-state operating conditions. The amount of electromagnetic thrust produced beyond the anode exit plane increases with increasing mass flow rate and increasing $J^{2} / \dot{m}$, in agreement with the predictions of Figure 14 . At $3 \mathrm{~g} / \mathrm{s}$ and $1.5 \times 10^{11} \mathrm{~A}^{2}-\mathrm{s} / \mathrm{kg}$, the amount of electromagnetic thrust created downstream of the anode is nearly $6 \%$ of the total electromagnetic thrust. Presumably this thrust is coupled through the magnetic field lines back into the thruster, but the details of how efficiently this process might occur remain to be explored. In addition, the downstream current may deposit thermal energy into the plume ${ }^{45}$ rather than the chamber plasma, resulting in a loss of electrothermal thrust.

Voltage and Efficiency. The radial electric field (Eqn. 7a) was numerically integrated from cathode to anode to provide an estimate of the potential drop across the plasma. The voltage calculations do not include fall voltages, but are still useful to predict voltage-current trends. Figure 16 shows the calculated plasma potential drop, and the experimentally determined total discharge voltage. The calculated plasma drop increases with increasing current, though at a slightly reduced rate compared to the total discharge voltage. In addition, the calculated potentials reproduce the dependence on mass flow rate seen in the total voltage measurements.

As noted in the ZT-1 thruster comparisons, the calculated plasma potential depends strongly on the value used for the electrical conductivity. A reduced conductivity will raise the calculated value of the potential drop across the plasma, without strongly affecting the calculated thrust. To evaluate this effect under extreme variations, the electrical conductivity expression used in the code (Equation 3 ) was reduced by a factor of 10 , and simulations were performed for $J^{2} / \dot{m}$ values of $5.1 \times 10^{10}$ and $1.5 \times 10^{11} \mathrm{~A}^{2}-\mathrm{s} / \mathrm{kg}$ at a mass flow rate of $3 \mathrm{~g} / \mathrm{s}$. Thrust values increased a modest $20 \%$ in both cases, but the plasma potentials increased by factors of 4 to 5 , bringing them close to the actual discharge voltages plotted in Figure 16. Changes in the plasma conductivity would thus appear to have a significant impact on total voltage, but minimal impact on the thrust. Choueiri et $a^{\beta 6}$ have shown that current driven instabilities may be generated in MPD thrusters, with an attendant decrease in plasma conductivity. Under such conditions, the total discharge voltage would be increased without a commensurate increase in thrust. The thrust efficiency, defined

$$
\eta_{T}=T^{2} /(2 \dot{m} P)
$$

where $T$ is thrust, $\dot{m}$ is propellant mass flow rate, and $P$ is power, would decrease under such operating conditions. The study of plasma instabilities and their effects on MPD thruster performance is clearly an area which warrants further investigation.

Using the potential calculations displayed in Figure 16, the amount of power deposited into the plasma can be compared with the total thruster power, determined experimentally. Due to uncertainties in the electrical conductivity a direct comparison is of limited use, but trends may be discerned which aid in thruster performance evaluation. Figure 17 displays the amount of power deposited into the plasma and the total power deposited into the thruster as a function of $J^{2} / \dot{m}$. The predicted trends in power with increasing $J^{2} / \dot{m}$ are similar for both the total thruster power and the power deposited solely into the plasma for all mass flow rates considered. Using the expression for efficiency defined above, both the total thruster efficiency $\left(\eta_{T}\right)$ and the efficiency with which power deposited in the plasma is converted to thrust (frozen flow efficiency, 
$\left.\eta_{f f}\right)$, can be separately evaluated. Figure 18 displays the experimentally evaluated thruster efficiency and the calculated frozen flow efficiency. The total thruster efficiency stays fairly flat in the $5-15 \%$ range, with the higher mass flow rates providing slightly higher thruster efficiencies. The frozen flow efficiencies are highest at the lower $J^{2} / \dot{m}$ values, ranging from $40 \%$ at $\dot{m}=1.5 \mathrm{~g} / \mathrm{s}$ to $60 \%$ at $\dot{m}=3 \mathrm{~g} / \mathrm{s}$. The frozen flow efficiencies decline with increasing $J^{2} / \dot{m}$, leveling out at a value around $37 \%$ at the higher $J^{2} / \dot{m}$ values. Assuming a smaller value for the electrical conductivity would result in even lower frozen flow efficiencies, because the amount of power deposited in the plasma would increase without significantly increasing the thrust. These results, while subject to the numerous approximations made in the model, predict that low frozen flow efficiencies will limit self-field MPD thruster performance. The impact of thruster geometry and propellant species on the frozen flow efficiency is under investigation.

\section{Concluding Remarks.}

A two dimensional magnetohydrodyanamics code has been developed to predict steady-state MPD thruster performance. The governing equations and corresponding methods of solution were outlined and discussed. Experimental comparisons were used to evaluate model calculations for two thruster geometries over a range of discharge currents and propellant mass flow rates. The self-field model accurately predicted thruster performance up to $J^{2} / \dot{m}$ values slightly below the onset of measured voltage instabilities. Methods to improve code performance have been outlined and discussed. Nonuniform grids should be incorporated to better model the sharp spatial gradients in temperature and pressure near the electrode surfaces. Improved estimates for the plasma transport coefficients and accurate electrode sheath models must be incorporated to accurately predict plasma potentials and total discharge voltages. Issues concerning the use of quasi-steady thruster data to verify steady-state model predictions must be addressed.

\section{Acknowledgements}

The author thanks his colleagues in the Low Thrust Propulsion Branch, NASA Lewis Research Center, for several useful discussions concerning the physics of MPD thrusters. Special thanks to Jim Gilland for providing his original experimental data for the HSFAT numerical comparisons.

\section{$\underline{\text { References }}$}

1. Seikel, G. R., York, T. M., and Condit, W. C., "Applied-Field Magnetoplasmdynamic Thrusters for OrbitRaising Missions", in Orbit-Raising and Maneuvering Propulsion: Research Status and Needs, Caveny, L. H. (ed), Progress in Astronautics and Aeronautics, vol. 89, 1984, pp. 260-286.

2. Gilland, J. H., Myers, R. M., and Patterson, M. J., "Multimegawatt Electric Propulsion System Design Considerations", AIAA Paper No. 90-2552, presented at the $21^{\text {st }}$ International Electric Propulsion Conference, July 18-20, 1990, Orlando, FL.

3. Sovey, J. S. and Mantenieks, M. A., "Perfromance and Lifetime Assessment of MPD Arc Thruster Technology", AIAA Paper No. 88-3211, presented at the $24^{\text {th }}$ Joint Propulsion Conference, July 11-13, 1988, Boston, MA.

4. Myers, R. M., Mantenieks, M. A., and Sovey, J. S., "Geometric Effects in Applied-Field MPD Thrusters", AIAA Paper No. 90-2669, presented at the $21^{\text {st }}$ International Electric Propulsion Conference, July 18-20, 1990, Orlando, FL. 
5. Tahara, H., Yasui, H., Kagaya, Y., and Yoshikawa, T., "Experimental and Theoretical Researches on Arc Structure in a Self-Field Thruster", AIAA Paper No. 87-1093, presented at the $19^{\text {th }}$ International Electric Propulsion Conference, May 11-13, 1987, Colorado Springs, CO.

6. Hugel, H., "Effect of Self-Magnetic Forces on the Anode Mechanism of a High Current Discharge", IEEE Transactions on Plasma Science, PS-8(4), December 1980, pp. 437-442.

7. Lawless, J. L. and Subramaniam, V. V., "Theory of Onset in Magnetoplasmadynamic Thrusters", J. Propulsion and Power, 3(2), March-April 1987, pp. 121-127.

8. Subramaniam, V. V. and Lawless, J. L., "Electrode-Adjacent Boundary Layer Flow in Magnetoplasmadynamic Thrusters", Phys. Fluids, 31(1), January 1988, pp. 201-209.

9. Niewood, E., Preble, J., Hastings, D., and Martinez-Sanchez, M., "Electrothermal and Modified Two Stream Instabilities in MPD Thrusters", AIAA Paper No. 90-2607, presented at the $21^{\text {st }}$ International Electric Propulsion Conference, July 18-20, 1990, Orlando, FL.

10. Rempfer, D., Auweter-Kurtz, M., Kaeppeler, H. J., and Maurer, M., "Investigation of Instabilities in MPD Thruster Flows Using a Linear Dispersion Relation", IEPC Paper No. 88-071, presented at the $20^{\text {th }}$ International Electric Propulsion Conference, October 3-6, 1988, Garmisch-Partenkirchen, W. Germany.

11. Wagner, H. P., Auweter-Kurtz, M., Roesgen, T., Messerschmid, E. W., and Kaeppeler, H. J., "Gradient Driven Instabilities in Stationary MPD Thruster Flows", AIAA Paper No. 90-2603, presented at the $21^{\text {st }}$ International Electric Propulsion Conference, July 18-20, 1990, Orlando, FL.

12. Nerheim, N. M. and Kelley, A. J., "A Critical Review of the State-of-the Art of the MPD Thrustor", AIAA Paper No. 67-688, presented at the AIAA Electric Propulsion and Plasmadynamics Conference, September 11-13, 1967, Colorado Springs, CO.

13. Martinez-Sanchez, M. and Hastings, D., "Physical Processes in MPD Plasmas", AFOSR-TR-89-1275, Final Report to AFOSR/NA, July 19, 1989.

14. Morozov, A. I., "Principle of Coaxial (Quasi-)Steady-State Plasma Accelerators", Sov. J. Plasma Phys., 16(2), February 1990, pp. 69-78.

15. Niewood, E. and Martinez-Sanchez, M., "Quasi One-Dimensional Numerical Simulation of Magnetoplasmadynamic Thrusters", AIAA Paper No. 90-2604, presented at the $21^{\text {st }}$ International Electric Propulsion Conference, July 18-20, 1990, Orlando, FL.

16. Auweter-Kurtz, M., Kurtz, H. L., Schrade, H. O., and Sleziona, P. C., "Numerical Modeling of the Flow Discharge in MPD Thrusters", AIAA Paper No. 87-1091, presented at the $19^{\text {th }}$ International Electric Propulsion Conference, May 11-13, 1987, Colorado Springs, CO.

17. Auweter-Kurtz, M., Glaser, S. F., Kurtz, H. L., Schrade, H. O., and Sleziona, P. C., "An Improved Code for Nozzle Type Steady State MPD Thrusters", IEPC Paper No. 88-040, presented at the $20^{\text {th }}$ International Electric Propulsion Conference, October 3-6, 1988, Garmisch-Partenkirchen, W. Germany.

18. Kurtz, H. L., Auweter-Kurtz, M., and Schrade, H. O., "Self-field MPD Thruster Design - Experimental and Theoretical Investigations", AIAA Paper No. 85-2002, presented at the $18^{\text {th }}$ International Electric Propulsion Conference, 1985, Alexandria, VA. 
19. Krulle, G., "Theoretical Treatment of Current, Mass Flow, and Related Distributions in MPD Plumes", AIAA Paper No. 72-501, presented at the AIAA $9^{\text {th }}$ Electric Propulsion Conference, April 17-19, 1972, Bethesda, MD.

20. Chanty, J. M. G. and Martinez-Sanchez, M., "Two-Dimensional Numerical Simulation of MPD Flows", AIAA Paper No. 87-1090, presented at the $19^{\text {th }}$ International Electric Propulsion Conference, May 11-13, 1987, Colorado Springs, CO.

21. Tahara, H., Yaasui, H., Kagaya, Y., and Yoshikawa, T., "Experimental and Theoretical Researches on Arc Structure in a Self-Field Thruster", AIAA Paper No. 87-1093, presented at the $19^{\text {th }}$ International Electric Propulsion Conference, May 11-13,, 1987, Colorado Springs, CO.

22. Minakuchi, H. and Kuriki, K., "Magnetoplasmadynamic Analysis of Plasma Acceleration", AIAA Paper No. 84-06, presented at the $17^{\text {th }}$ International Electric Propulsion Conference, May 28-31, 1984, Tokyo, Japan.

23. Martinez-Sanchez, M., "Structure of Self-Field Accelerated Plasma Flows", J. Propulsion and Power, 7(1), Jan-Feb 1991, pp.56-64.

24. Kuriki, K., Kunii, Y, and Shimizu, Y., "Idealized Model for Plasma Acceleration in an MHD Channel", AIAA Journal, 21(3), March 1983, pp. 322-326.

25. Park, W. and Choi, D., "Numerical Analysis of MPD Arcs for Plasma Acceleration", IEEE Transactions on Plasma Science, PS-15(5), October 1987.

26. Sleziona, P. C., Auweter-Kurtz, M., Schrade, H. O., and Wegmann, T., "Comparison of Numerical and Experimental Investigations of Nozzle Type MPD Accelerators", AIAA Paper No. 90-2663, presented at the $21^{\text {tt }}$ International Electric Propulsion Conference, July 18-20, 1990, Orlando, FL.

27. Seals, R. K. and Hassan, H. A., "Analysis of MPD Arcs with Nonequilibrium Ionization", AIAA Journal, bf 6(12), December 1968, pp. 2273-2278.

28. Sleziona, P. C., Auweter-Kurtz, M., and Schrade, H. O., "Numerical Codes for Cylindrical MPD Thrusters", IEPC Paper No. 88-038, presented at the $20^{\text {th }}$ International Electric Propulsion Conference, October 3-6, 1988, Garmisch-Partenkirchen, W. Germany.

29. Mayer, W., "Numerische Berechnung der Stremung im Zylindrischen MPD-Triebwerk mit einen FinitenVolumen-Verfahren", Universitat Stuttgart, Dec 1989, Dissertation pp. 1-62, W. Germany.

30. Sleziona, P. C., Auweter-Kurtz, M., and Schrade, H. O., "Numerical Evaluation of MPD Thrusters", AIAA Paper No. 90-2602, presented at the $21^{\text {st }}$ International Electric Propulsion Conference, July 18-20, 1990, Orlando, FL.

31. Sleziona, P.C., Universitat Stuttgart, Germany; personal communication, August, 1990.

32. Auweter-Kurtz, M., Universitat Stuttgart, Germany; personal communication, March, 1991.

33. Tanaka, M. and Kimura, I., "Current Distribution and Plasma Acceleration in MPD Arcjets with Applied Magnetic Fields", J. Propulsion and Power, 4(5), Sept-Oct 1988, pp. 428-436. 
34. Sutton, G. W. and Sherman, A., Engineering Magnetohydrodynamics, McGraw-Hill Book Co., New York, 1965.

35. Hughes, W. F. and Young, F. J., The Electromagnetodynamics of Fluids, J. Wiley \& Sons, pub., New York, 1966, pp. 5-7.

36. Choueiri, E. Y., Kelley, A. J., and Jahn, R. G. , "Current Driven Instabilities of an Electromagnetically Accelerated Plasma", IEPC Paper No. 88-042, presented at the $20^{\text {th }}$ International Electric Propulsion Conference, October 3-6, 1988, Garmisch-Partenkirchen, W. Germany.

37. Cambel, A. B., Plasma Physics and Magnetofluidmechanics, McGraw-Hill Book Co., New York, 1963.

38. Greenspan, D. G., Discrete Numerical Methods in Physics and Engineering, Academic Press, New York, 1974.

39. Kurtz, H. L., Auweter-Kurtz, M., Glocker, B., Habiger, H., Merke, W., and Schrade, H. O., "Cylindrical Steady-State MPD Thruster", IEPC paper 88-025, presented at the $20^{\text {th }}$ International Electric Propulsion Conference, October 3-6, 1988, Garmisch-Partenkirchen, W. Germany.

40. Gilland, J. H., Kelley, R. A., and Jahn, R. G., "MPD Thruster Scaling", AIAA Paper No. 87-0997, presented at the $19^{\text {th }}$ International Electric Propulsion Conference, May 11-13, 1987, Colorado Springs, CO.

41. Gilland, J. H., "The Effect of Geometrical Scale Upon MPD Thruster Behavior", M.S. Thesis No. 1811T, Department of Mechanical and Aerospace Engineering, Princeton University, Princeton, NJ, March 1988.

42. Auweter-Kurtz, M., Glocker, B., Kurtz, H. L., Loesener, O., Schrade, H. O., Tubanos, N., Wegmann, T., Willer, D., and Polk, J., "Cathode Phenomena in Plasma Thrusters", AIAA Paper No. 90-2662, presented at the $21^{\text {st }}$ International Electric Propulsion Conference, July 18-20, 1990, Orlando, FL.

43. Jahn, R. G., Physics of Electric Propulsion, McGraw-Hill Book Co., New York, 1968, pp. 241-246.

44. Wolff, M., "A High Performance MPD Thruster", M.S.E. Thesis, Princeton University, Princeton, NJ, Oct. 1983.

45. Myers, R. M., "Plume Characteristics of MPD Thrusters: A Preliminary Examination", AIAA Paper No. 89-2832, presented at the $25^{\text {th }}$ Joint Propulsion Conference, July 10-14, 1989, Monterey, CA. NASA CR-185130, September 1989. 


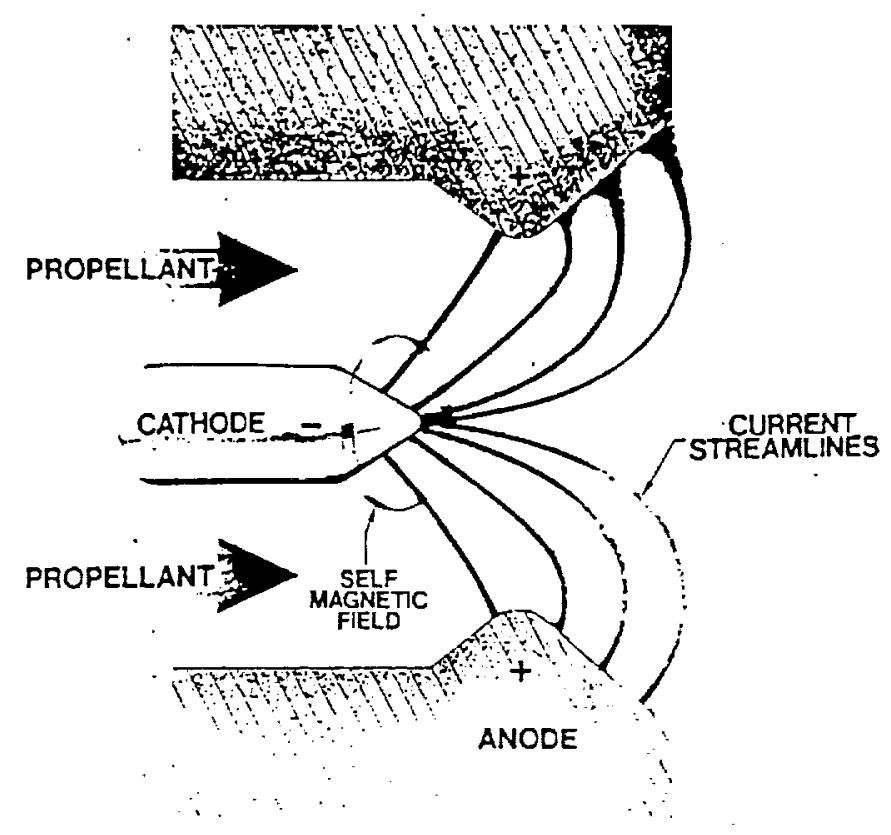

Figure 1. Self-field MPD thruster diagram.

\section{Program Outline}

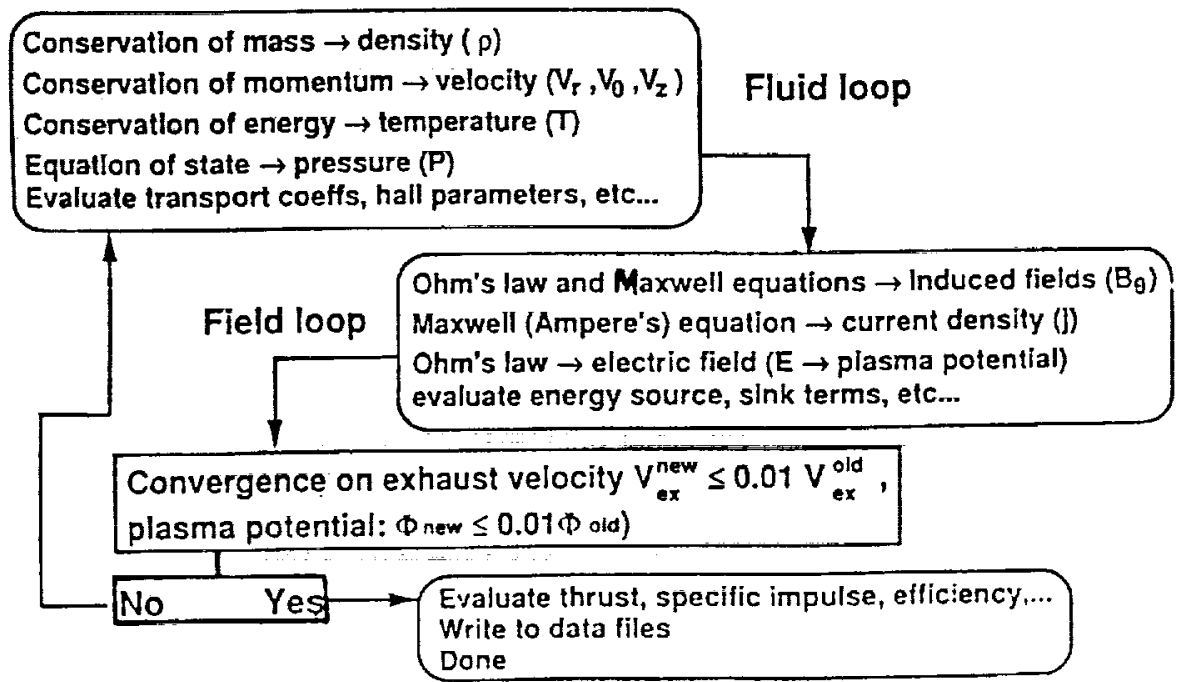

Figure 2. MPD thruster program outline. 


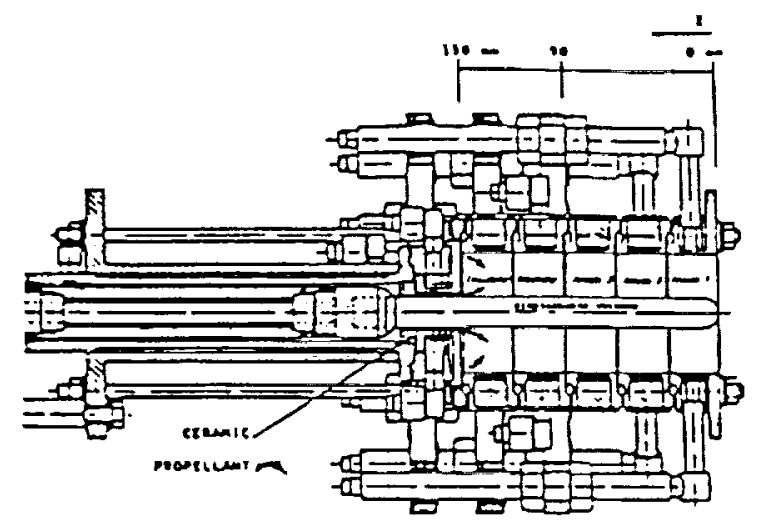

Figure 3(a). ZT-1 thruster schematic

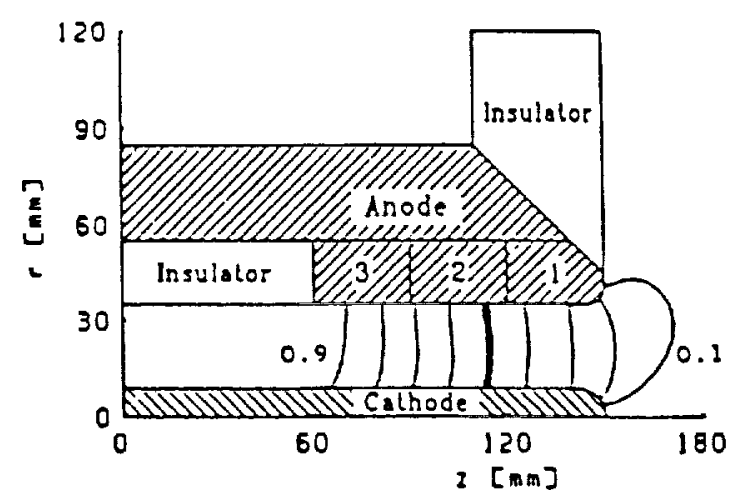

Figure 3(b). U. Stuttgart enclosed current predictions. Contour levels every $10 \%$.

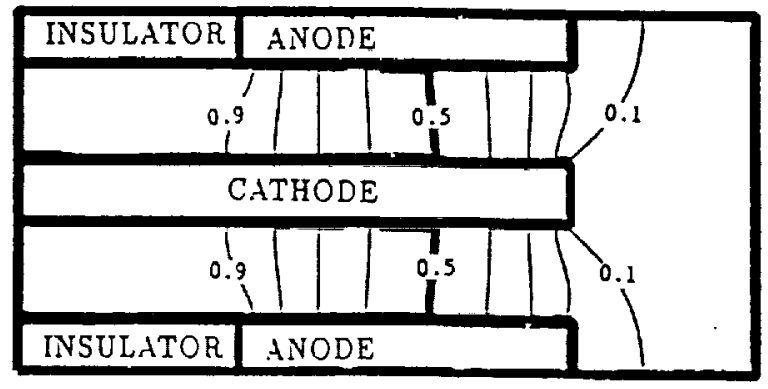

Figure $3(\mathrm{c})$. NASA LeRC enclosed current predictions. Contour levels every $10 \%$.

Figure 3. Predicted enclosed current contour comparisons for the ZT-1 thruster operating at $6000 \mathrm{~A}, 6 \mathrm{~g} / \mathrm{s}$, argon propellant. 

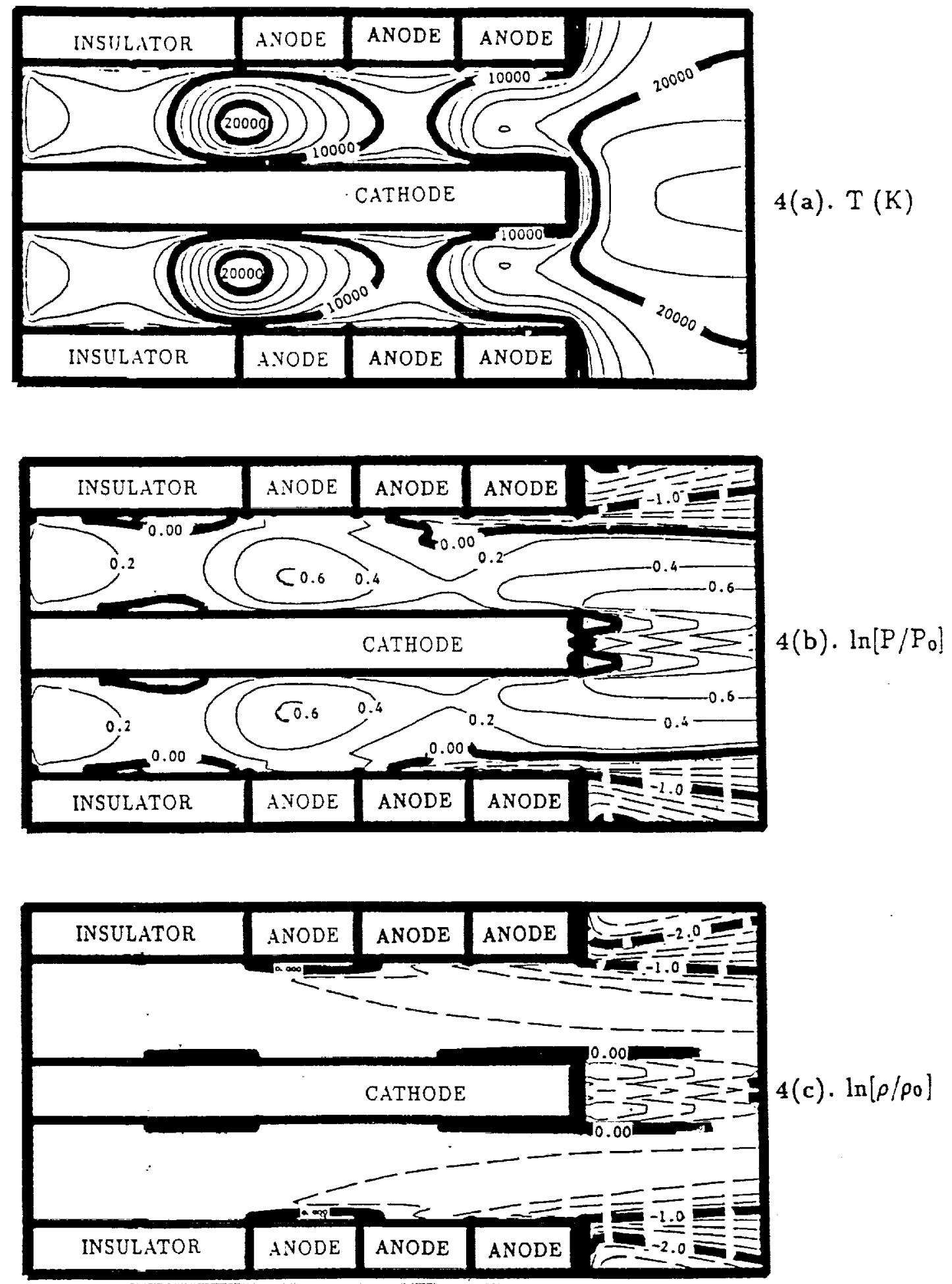

Figure 4. Predicted (a) temperature, (b) pressure, and (c) density contours for ZT-1 thruster at $6000 \mathrm{~A}, 6 \mathrm{~g} / \mathrm{s}$, argon propellant. Pressure and density are normalized to inlet values: $P_{0}=1.1 \times 10^{3} \mathrm{~N} / \mathrm{m}^{2}, \rho_{0}=1.8 \times 10^{-3} \mathrm{~kg} / \mathrm{m}^{3}$. Plots $(b)$ and $(c)$ are $\log _{10}$ of normalized values. 

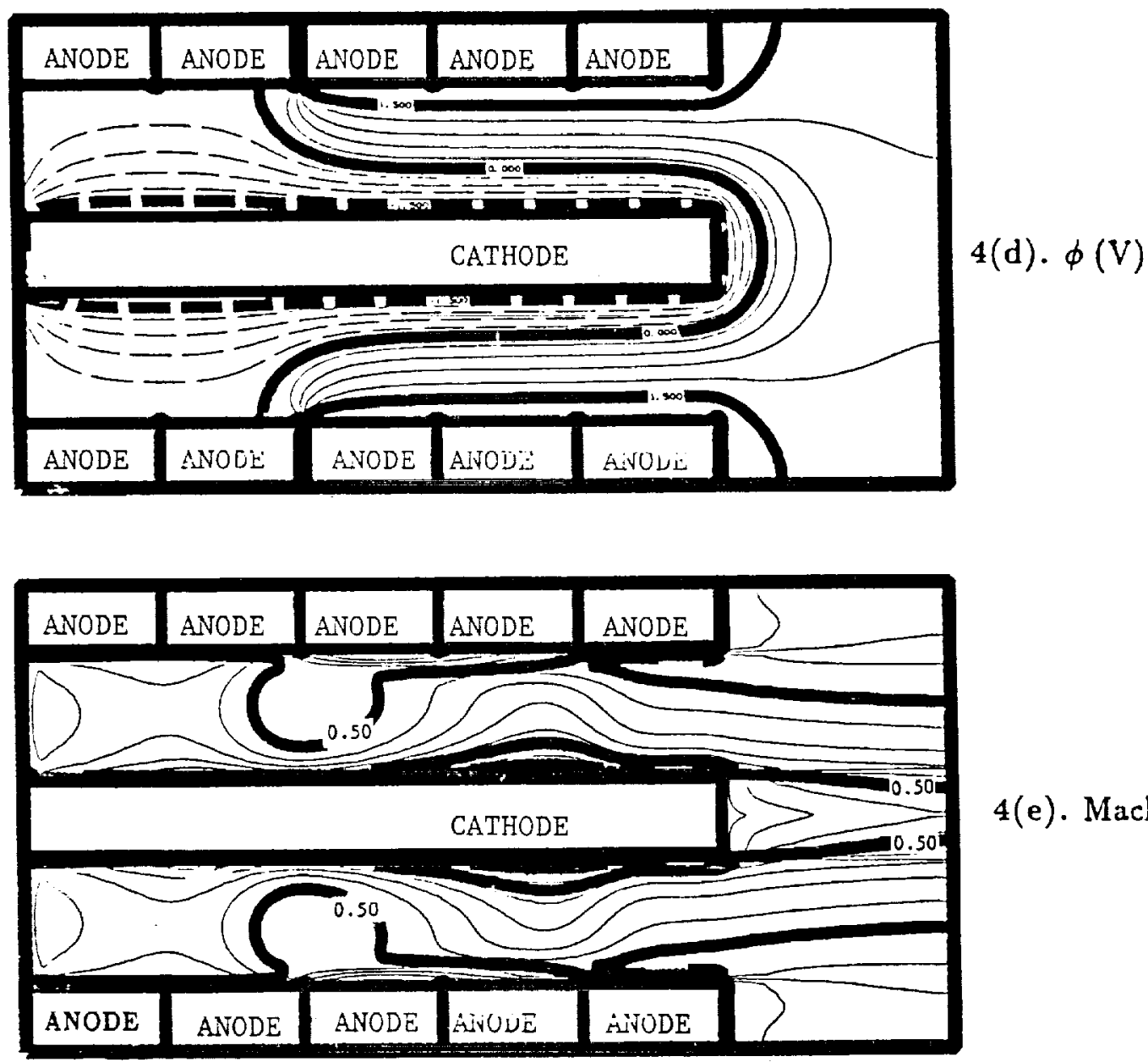

4(e). Mach \#

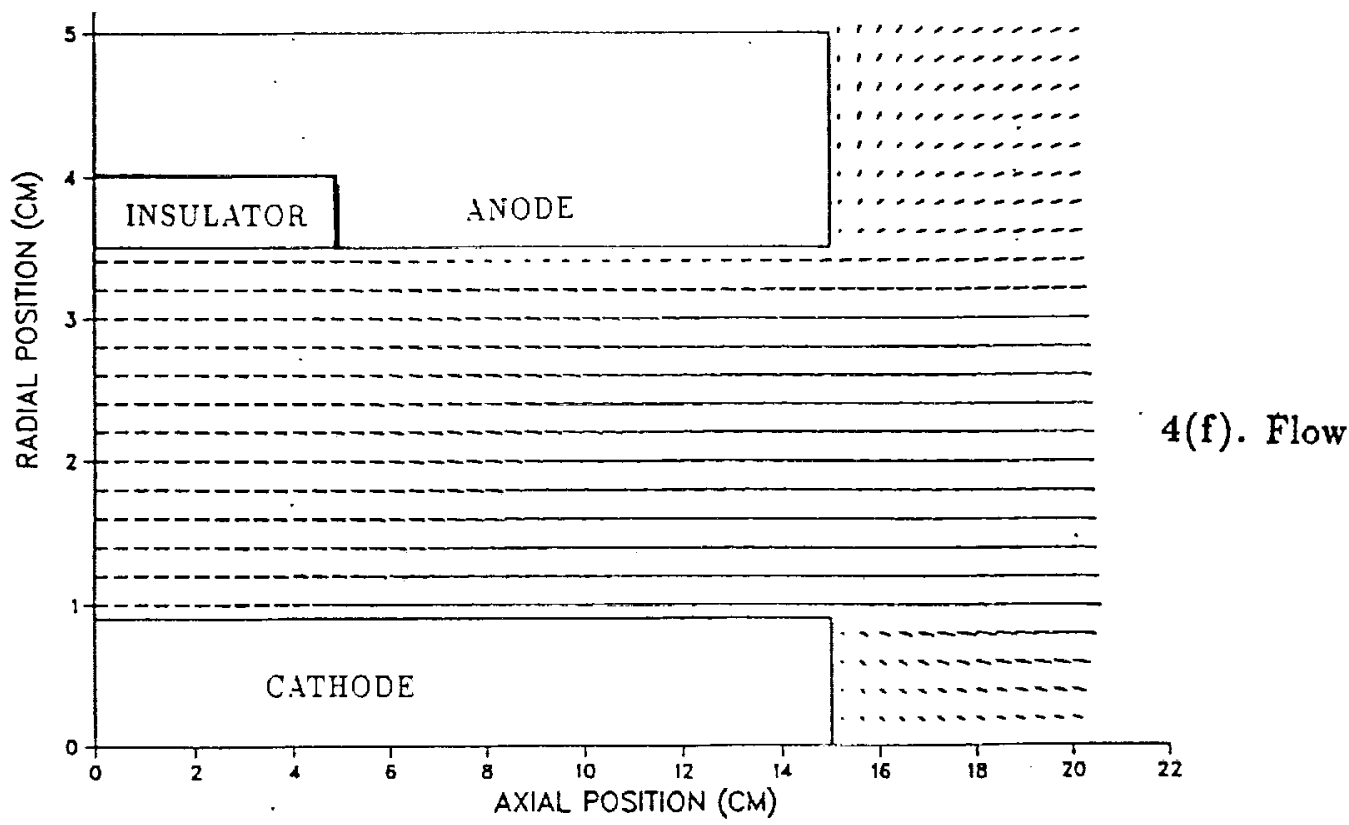

Figure 4, cont. Predicted (d) electric potential, (e) Mach number, and (f) velocity flow distribution for ZT-1 thruster operating at $6000 \mathrm{~A}, 6 \mathrm{~g} / \mathrm{s}$. 

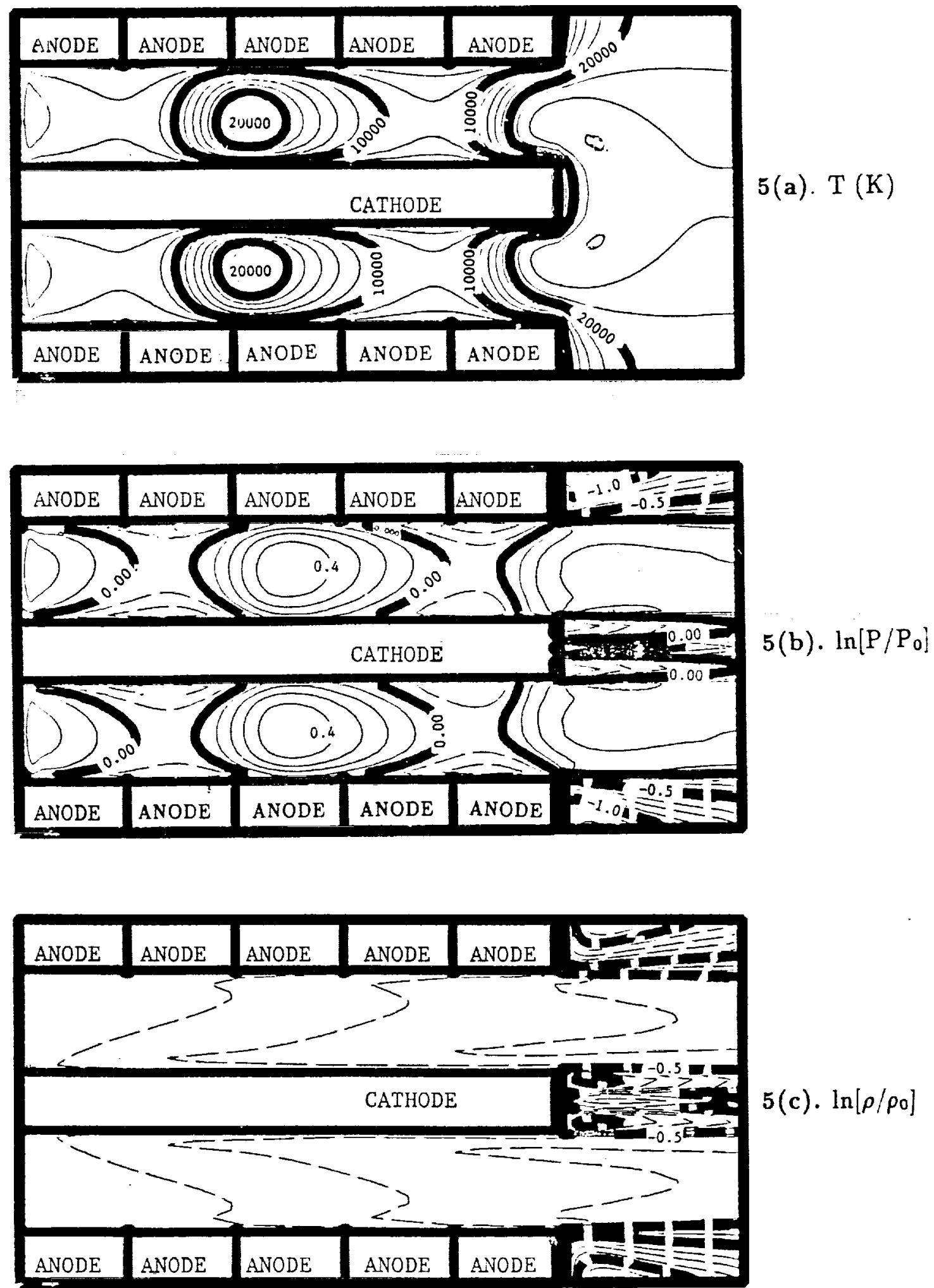

Figure 5. Predicted (a) temperature, (b) pressure, and (c) density contours for ZT-1 thruster without insulated anode segments, operating at $6000 \mathrm{~A}, 6 \mathrm{~g} / \mathrm{s}$, argon propellant. Pressure and density are normalized to inlet values: $P_{0}=1.1 \times 10^{3} \mathrm{~N} / \mathrm{m}^{2}, \rho_{0}=1.8 \times 10^{-3} \mathrm{~kg} / \mathrm{m}^{3}$. Plots (b) and (c) are $\log _{10}$ of normalized values. 

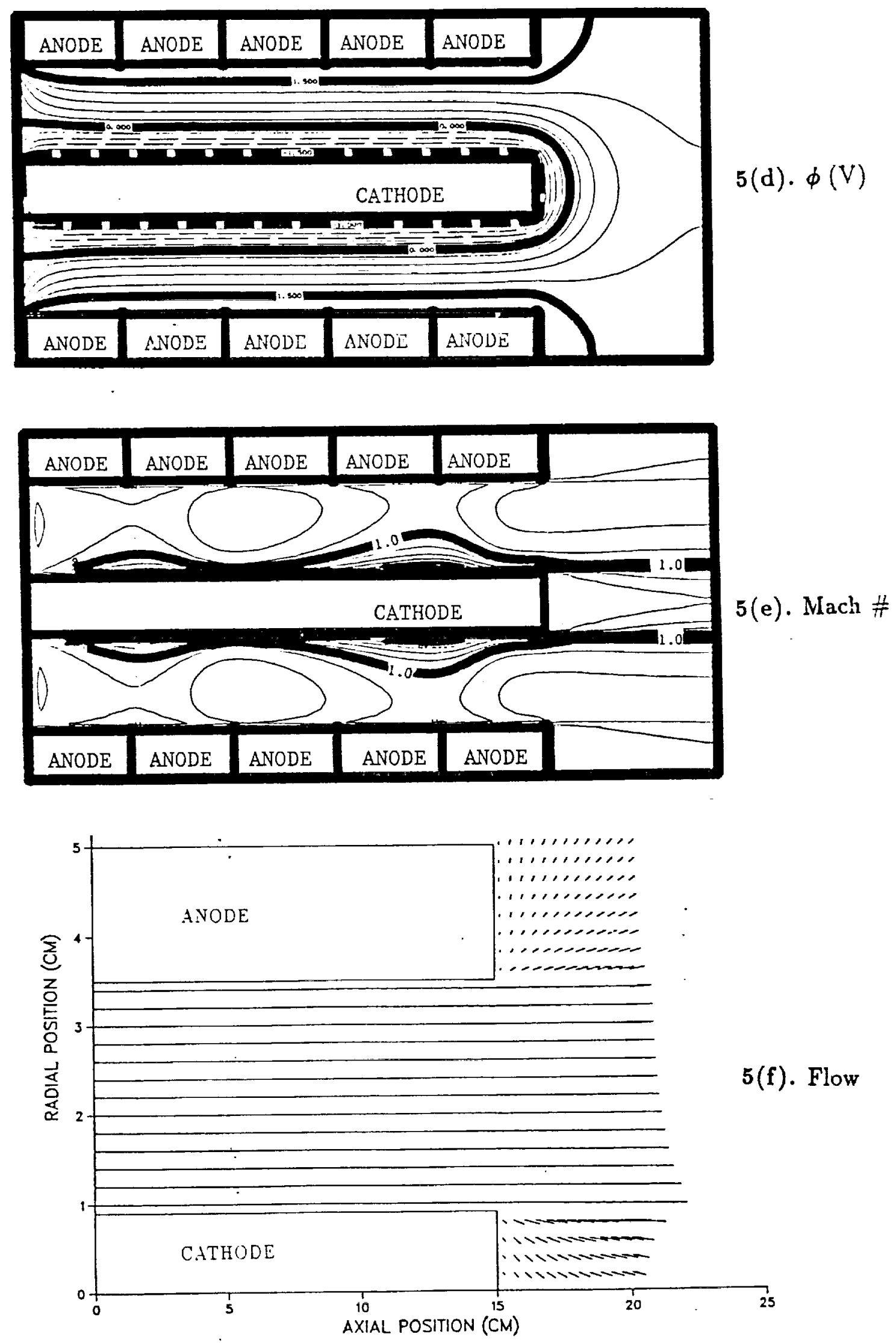

Figure 5, cont. Predicted (d) electric potential, (e) Mach number, and (f) velocity flow distribution for ZT-1 thruster without insulated anode segments, operating at $6000 \mathrm{~A}, 6 \mathrm{~g} / \mathrm{s}$. 


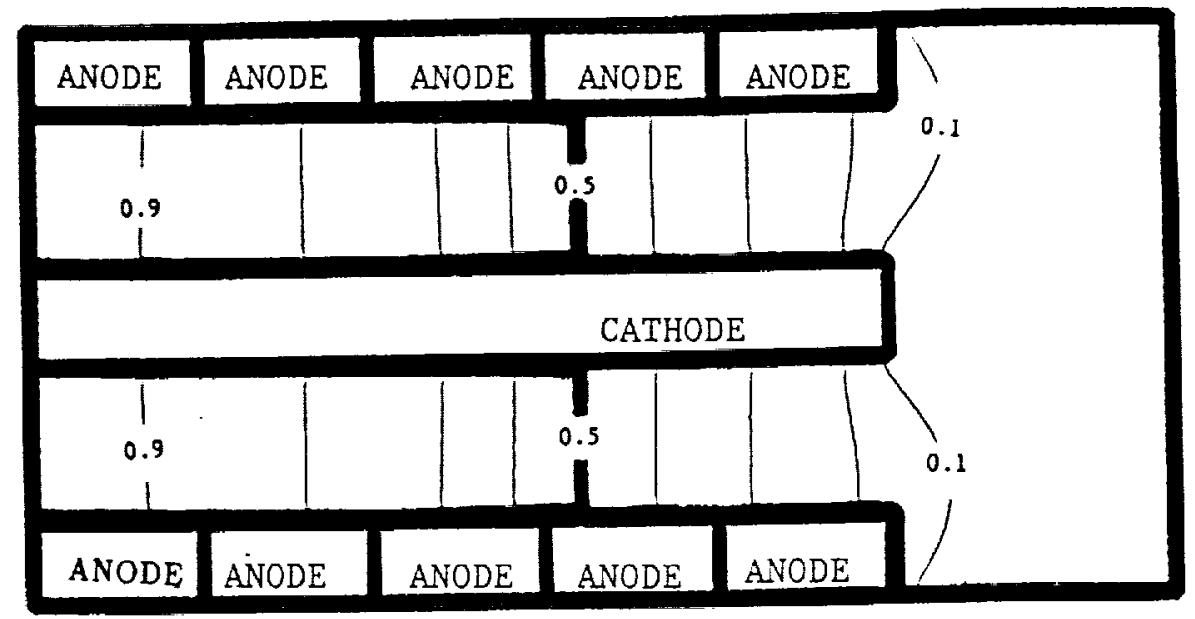

Figure 5(g) Predicted enclosed current contours for the ZT-1 thruster without insulating anode segments, operating at $6000 \mathrm{~A}$ and $6 \mathrm{~g} / \mathrm{s}$, argon propellant.

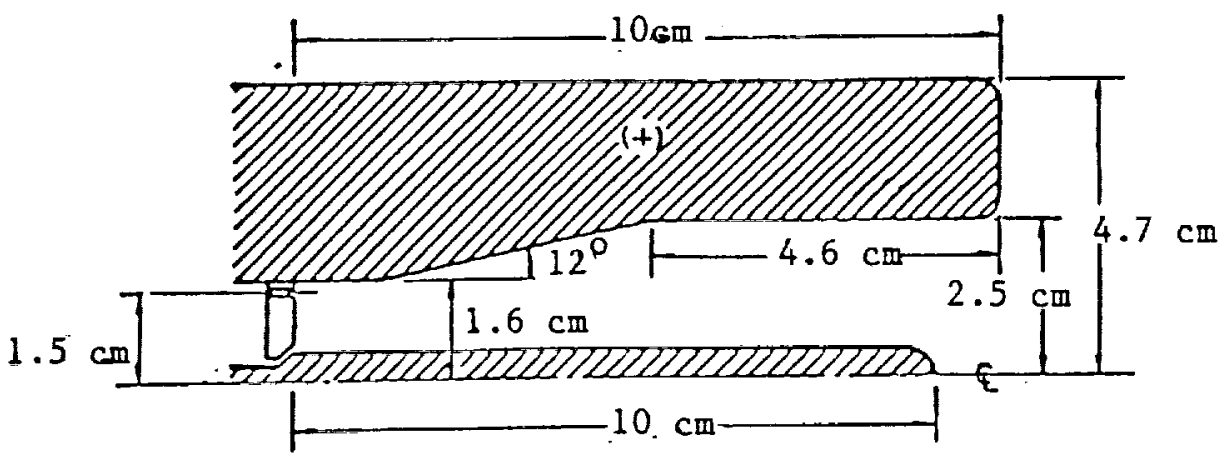

Figure 6. Half-scale flared anode thruster (HSFAT) diagram. 


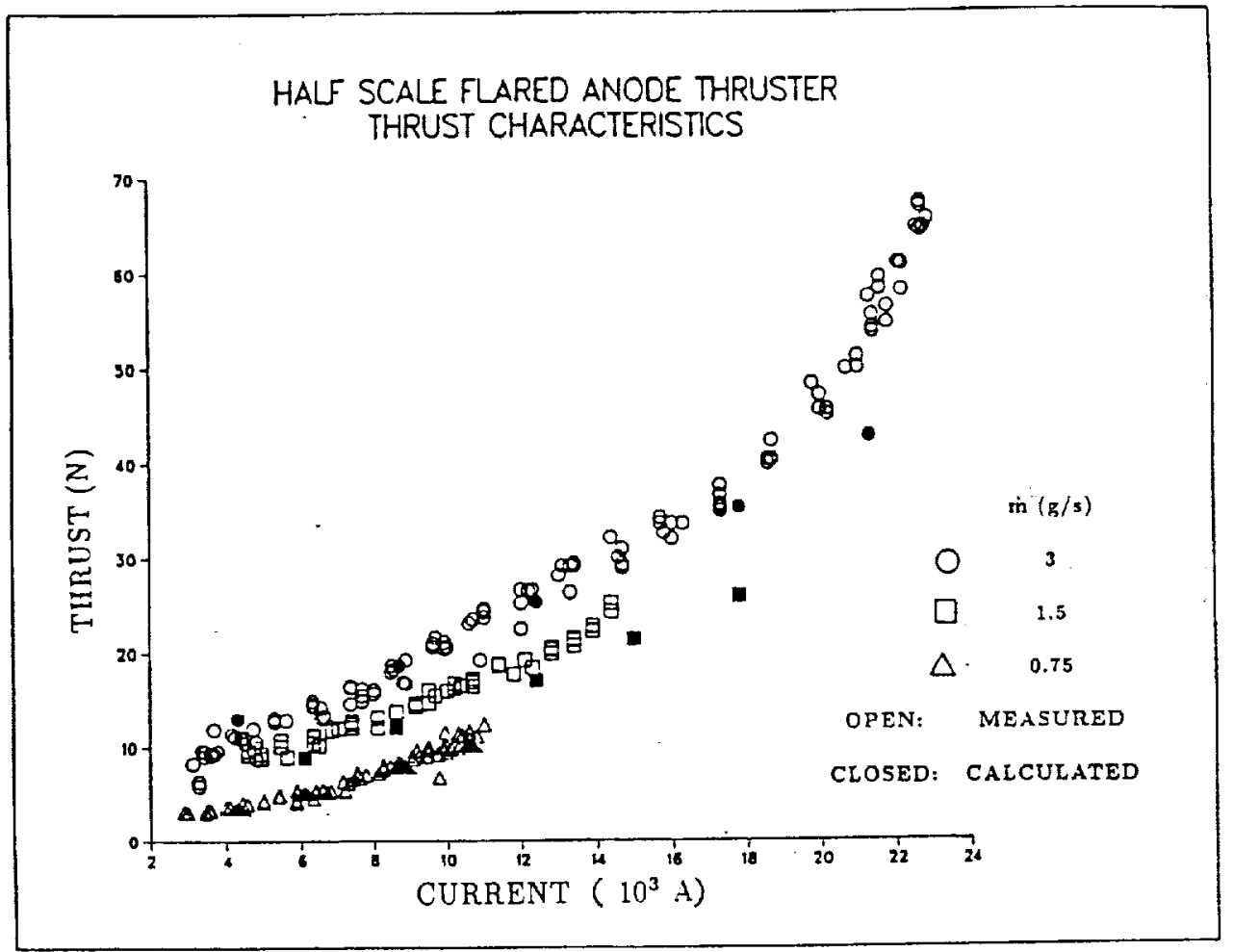

Figure 7. HSFAT thrust characteristics, argon propellant.

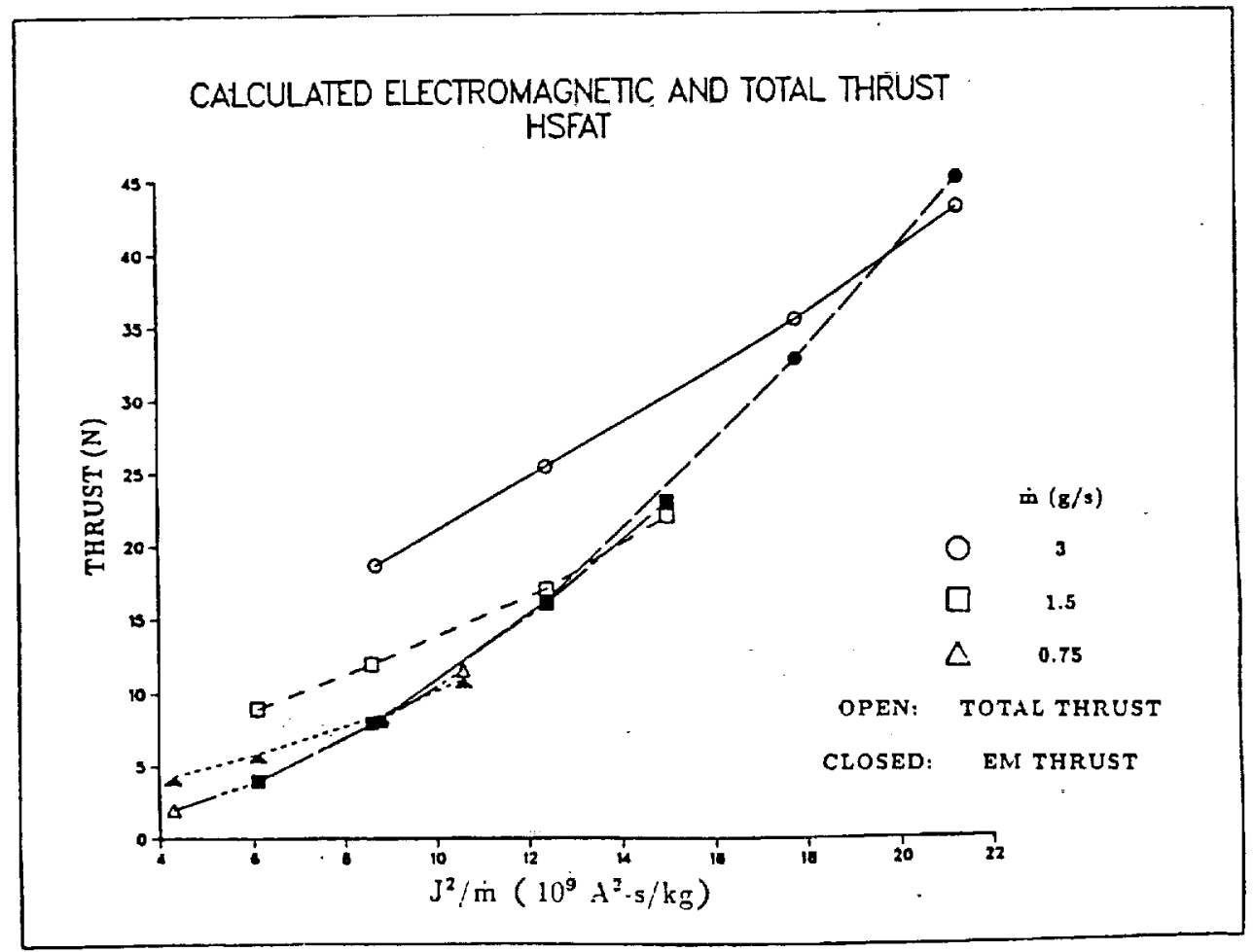

Figure 8. Calculated electromagnetic and total thrust for HSFAT, argon propellant. 


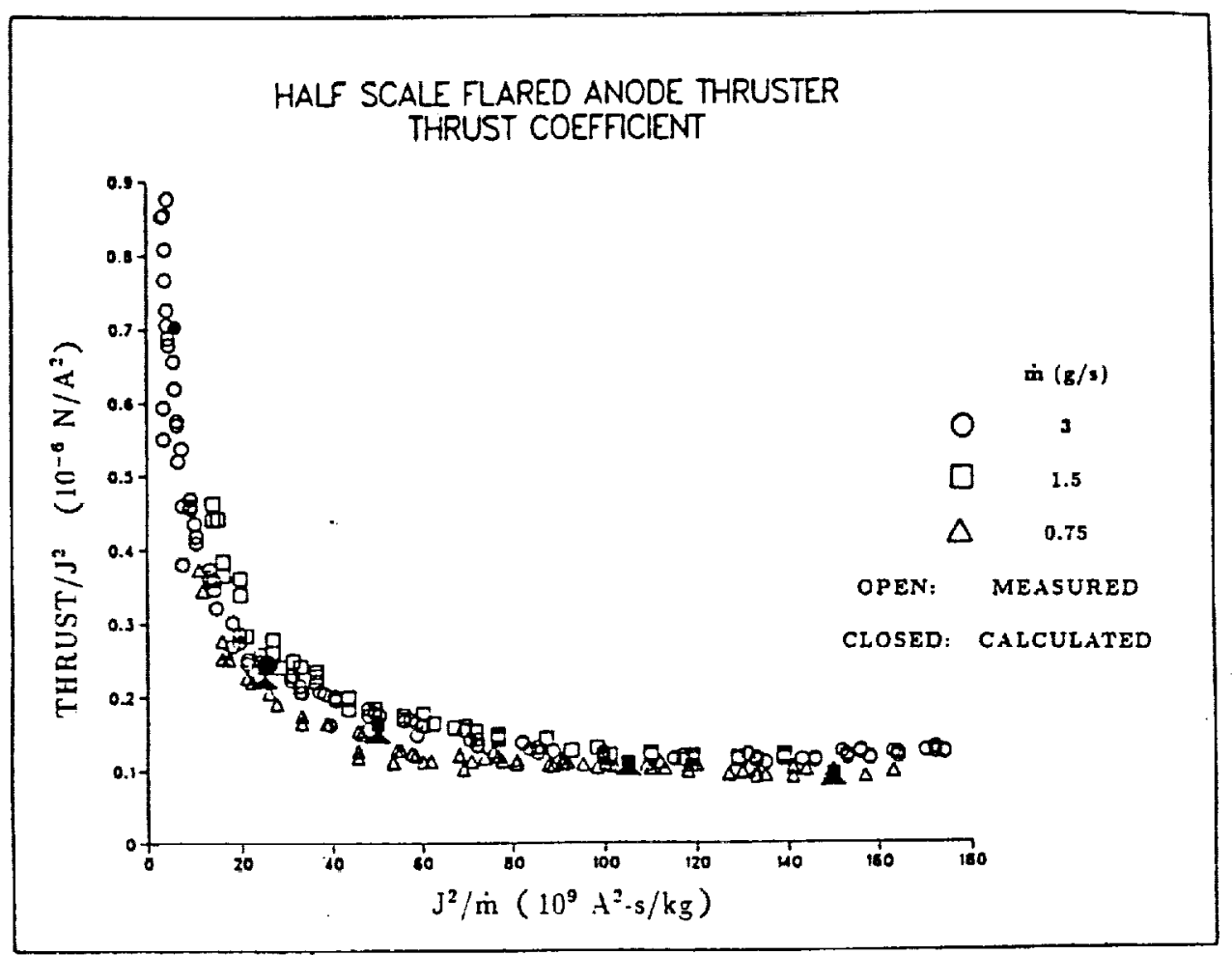

Figure 9. HSFAT thrust coefficients, argon propellant.

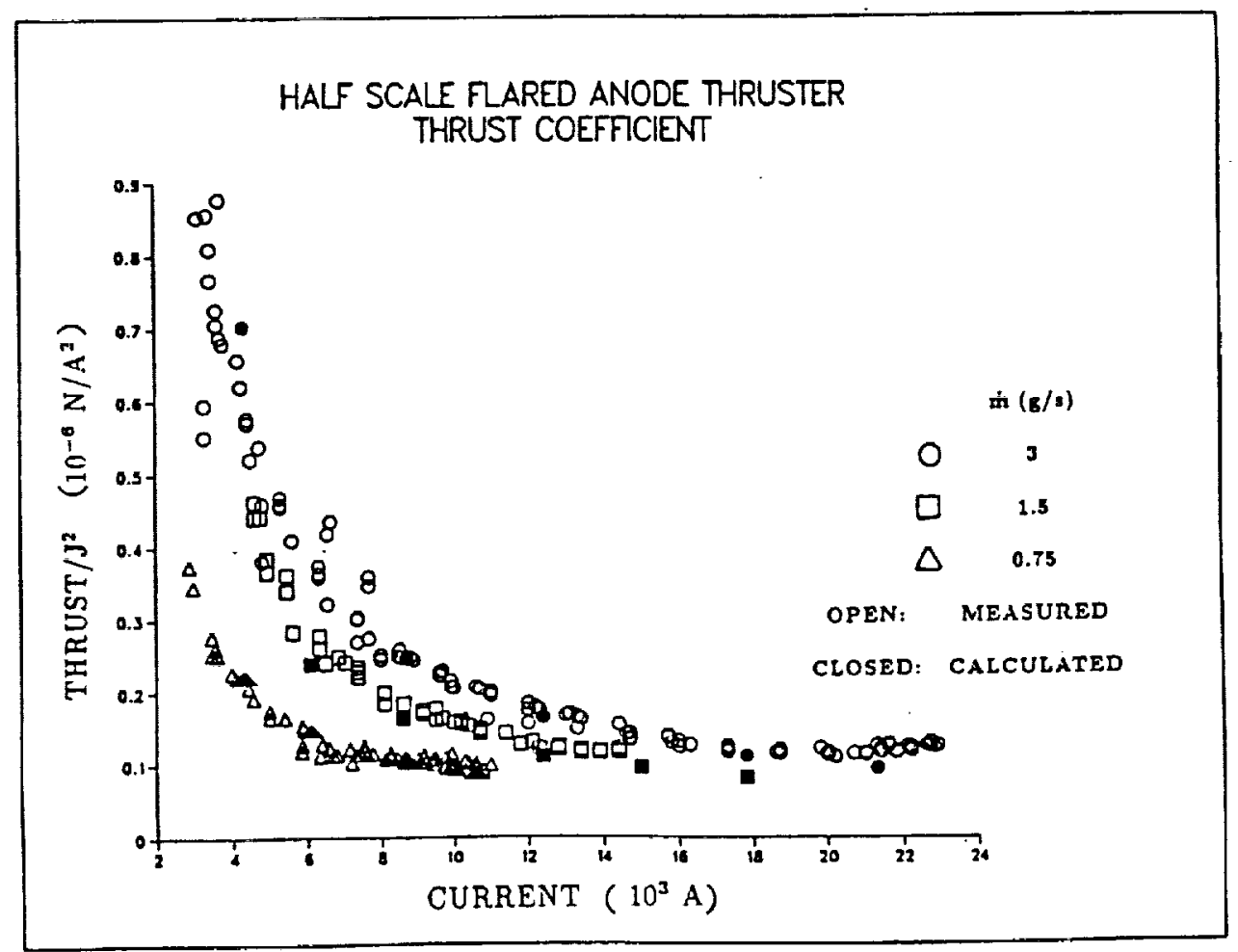

Figure 10. HSFAT thrust coefficients plotted against current to show mass flow rate dependence. 


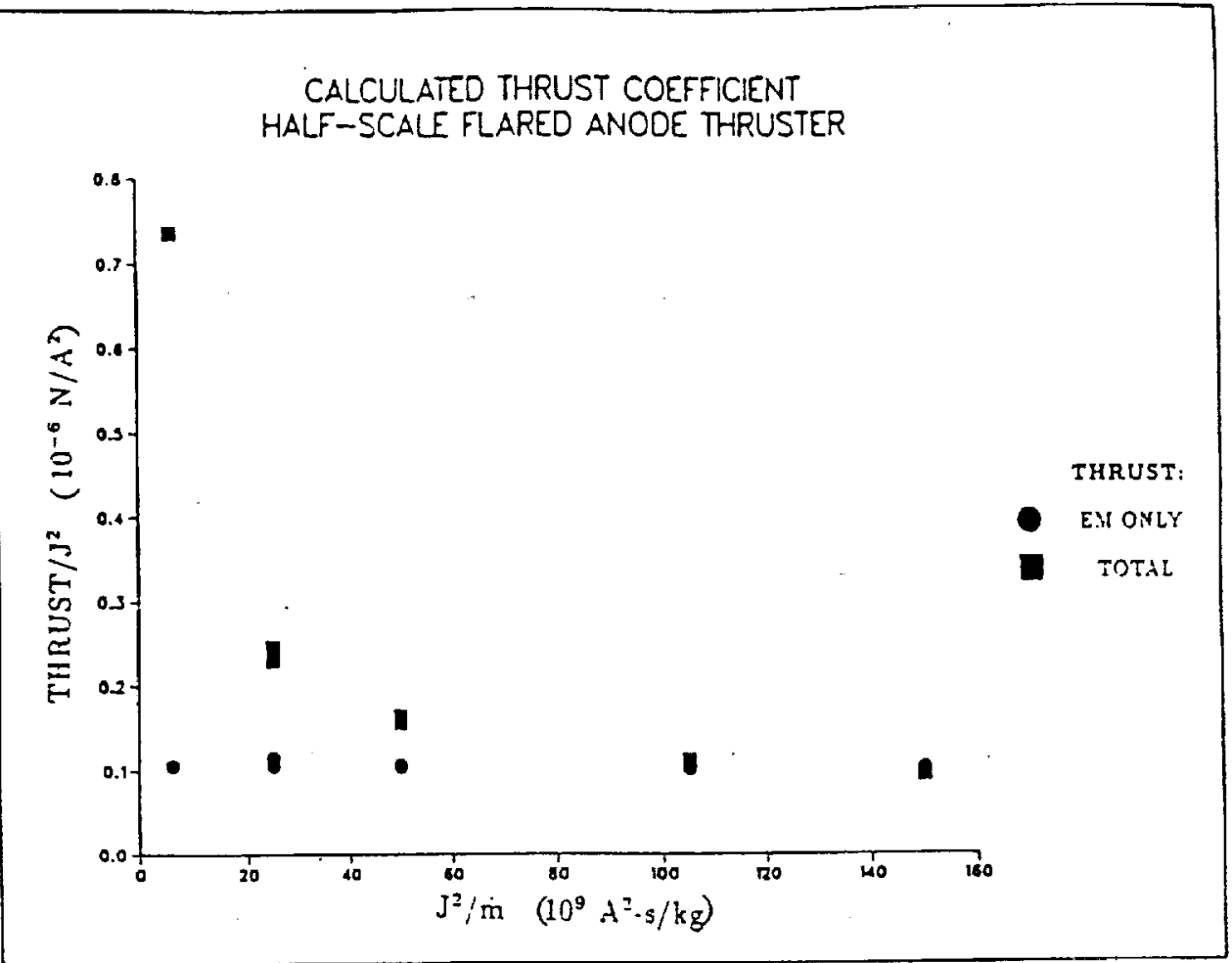

Figure 11. HSFAT electromagnetic and total thrust coefficients.

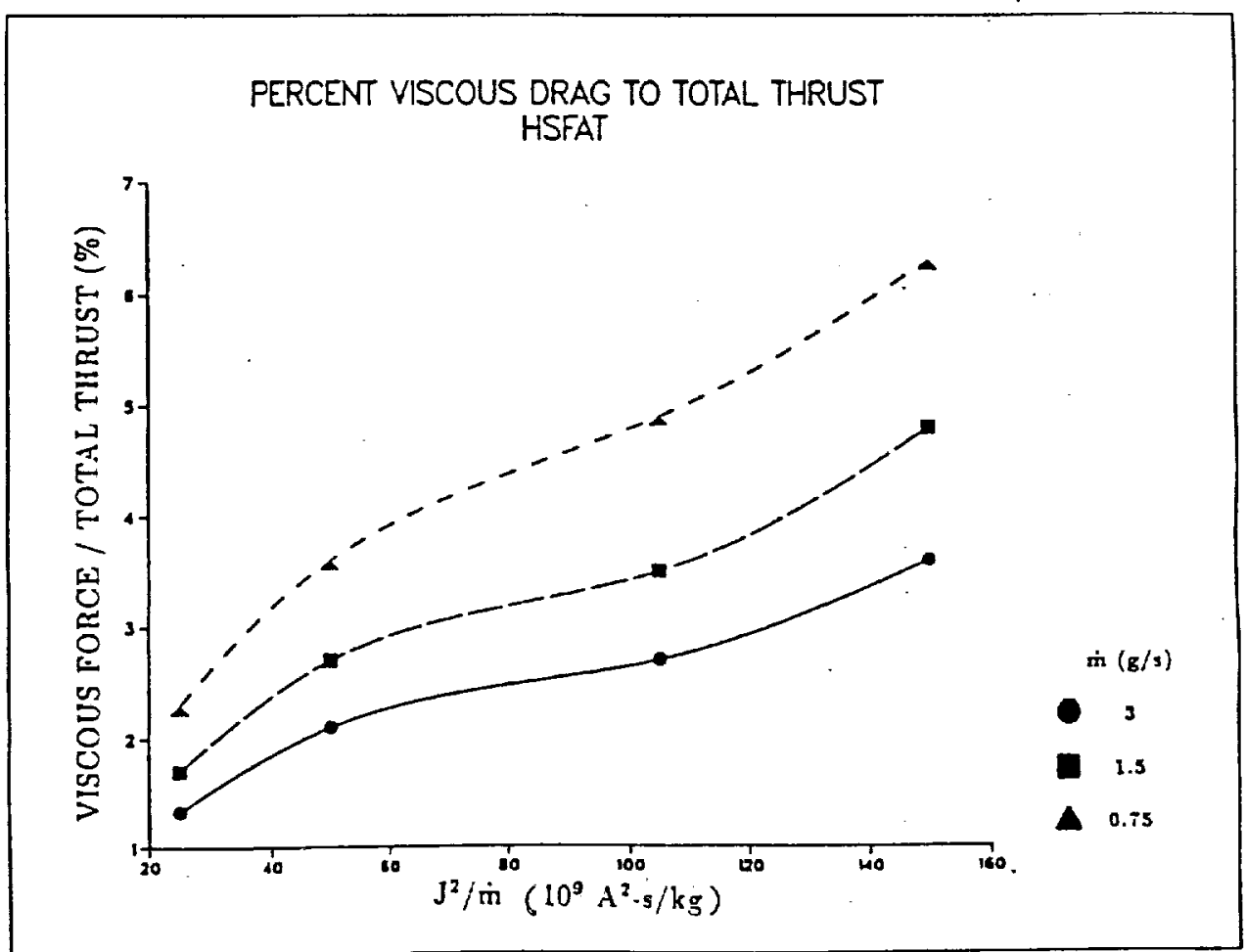

Figure 12. Ratio of viscous drag to total thrust, HSFAT thruster, argon propellant. 


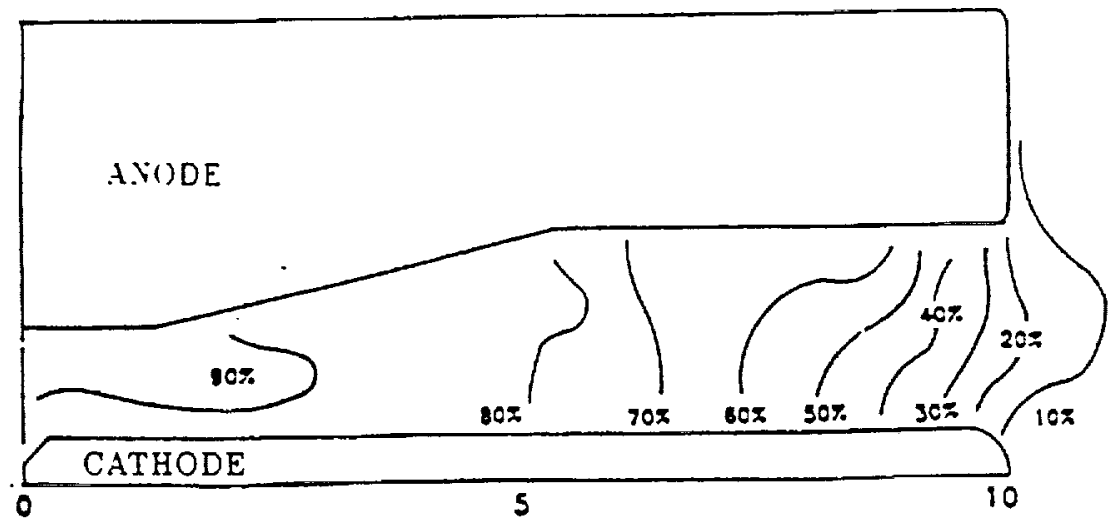

(a) $7.9 \mathrm{kA}, 3 \mathrm{~g} / \mathrm{s}\left(2.1 \times 10^{10} \mathrm{~A}^{2}-\mathrm{s} / \mathrm{kg}\right.$

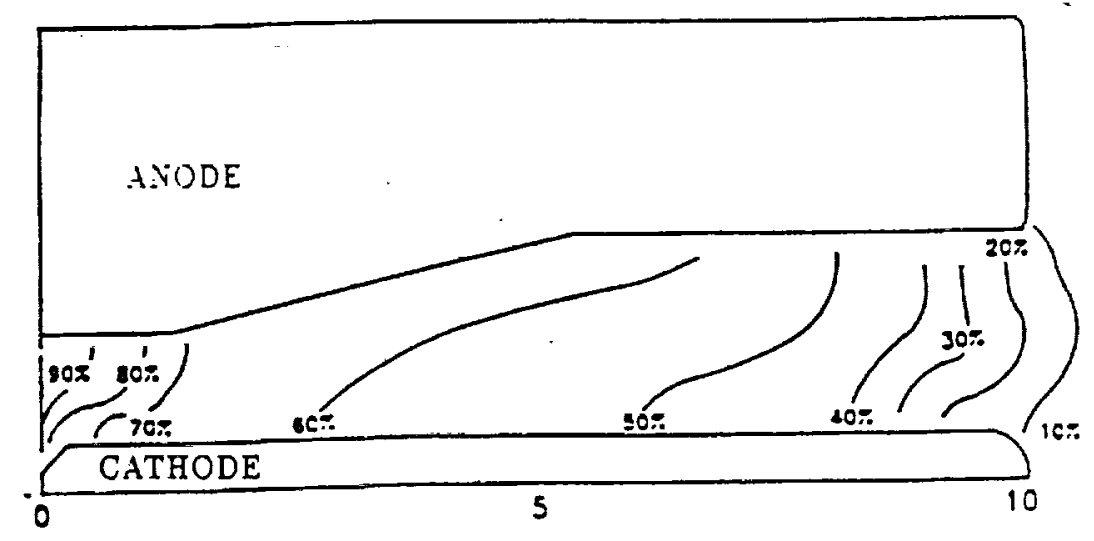

(b) $17.8 \mathrm{kA}, 3 \mathrm{~g} / \mathrm{s}\left(1.05 \times 10^{11} \mathrm{~A}^{2}-\mathrm{s} / \mathrm{kg}\right)$

Figure 13. Measured enclosed current contours, HSFAT, argon propellant. 

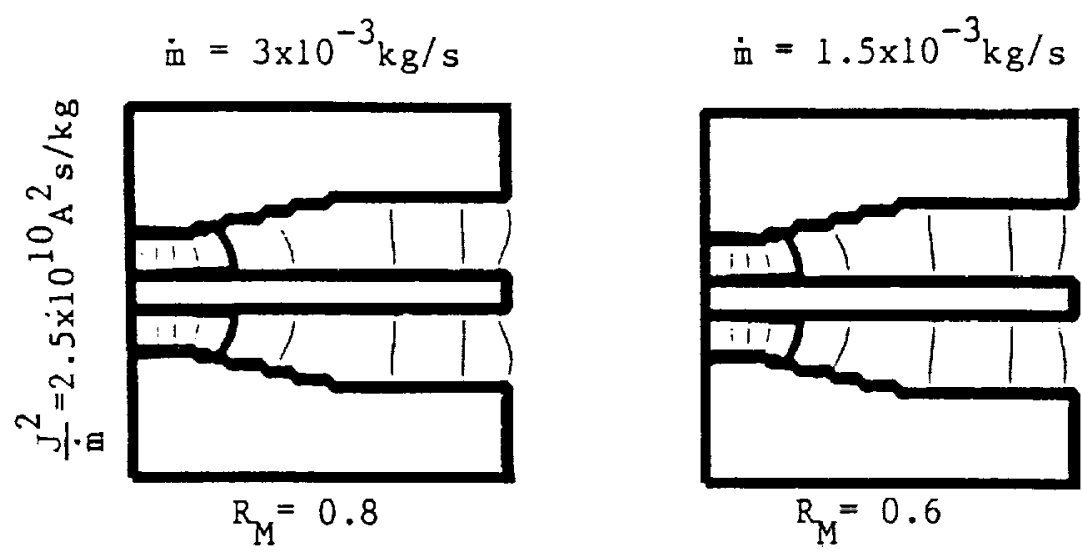

$\dot{\mathrm{n}} \equiv 7.5 \times 10^{-4} \mathrm{~kg} / \mathrm{s}$
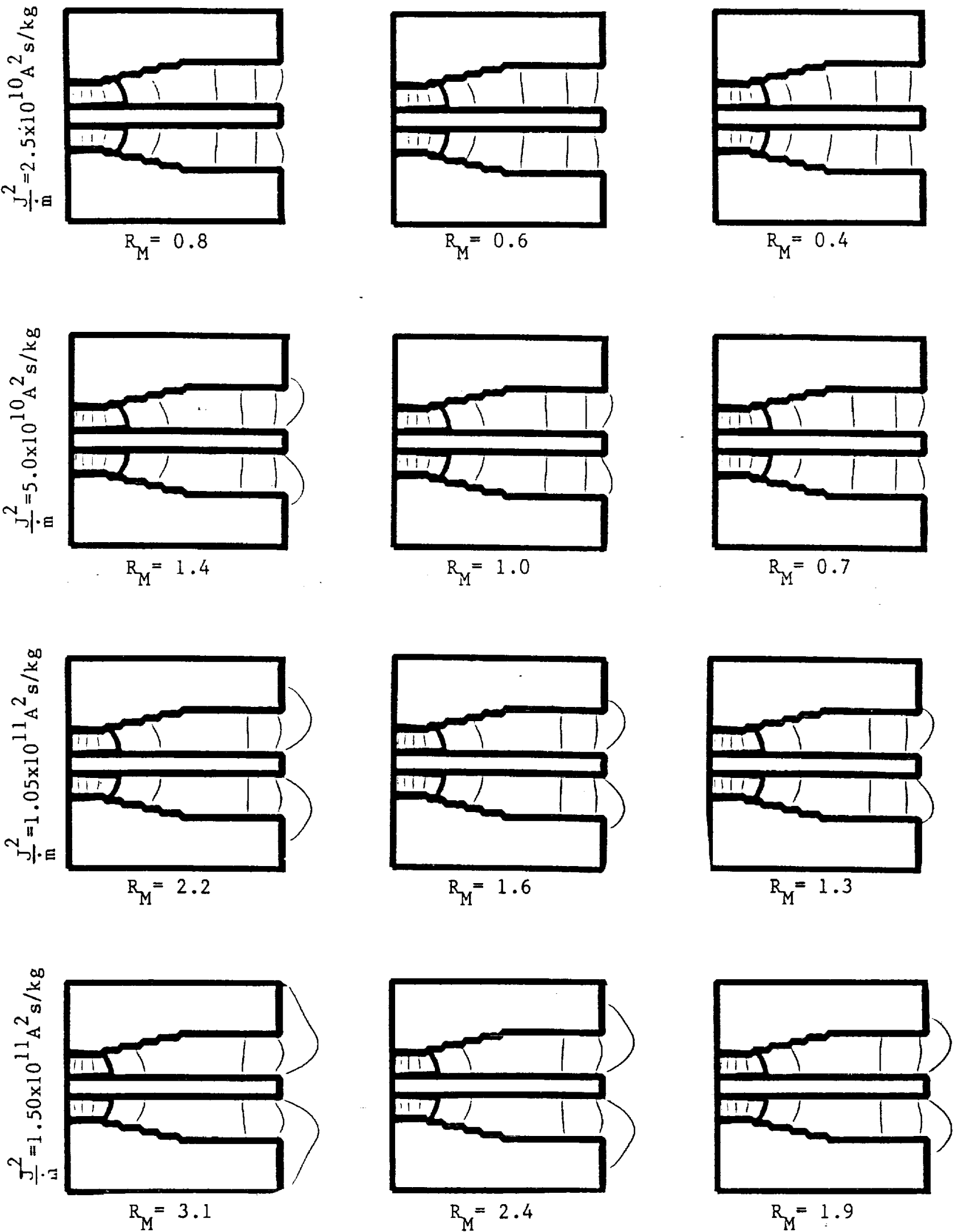

Figure 14.Predicted enclosed current contours, HSFAT, plotted as a matrix of mass flow rate and $J^{2} / \dot{m}$. Average magnetic Reynolds numbers are shown for each operating condition. 


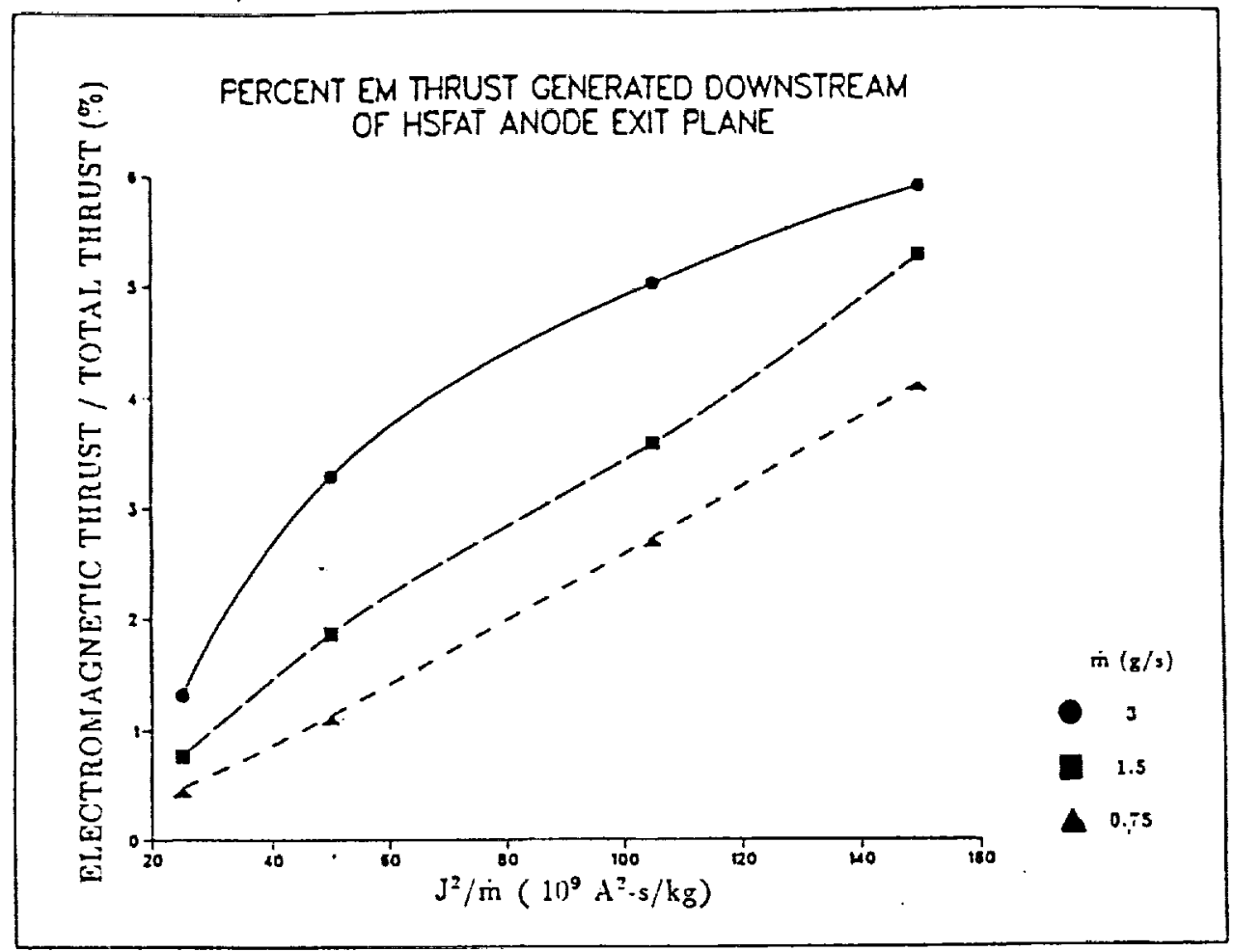

Figure 15. Predicted precentage of electromagnetic thrust generated downstrean of the HSFAT anode.

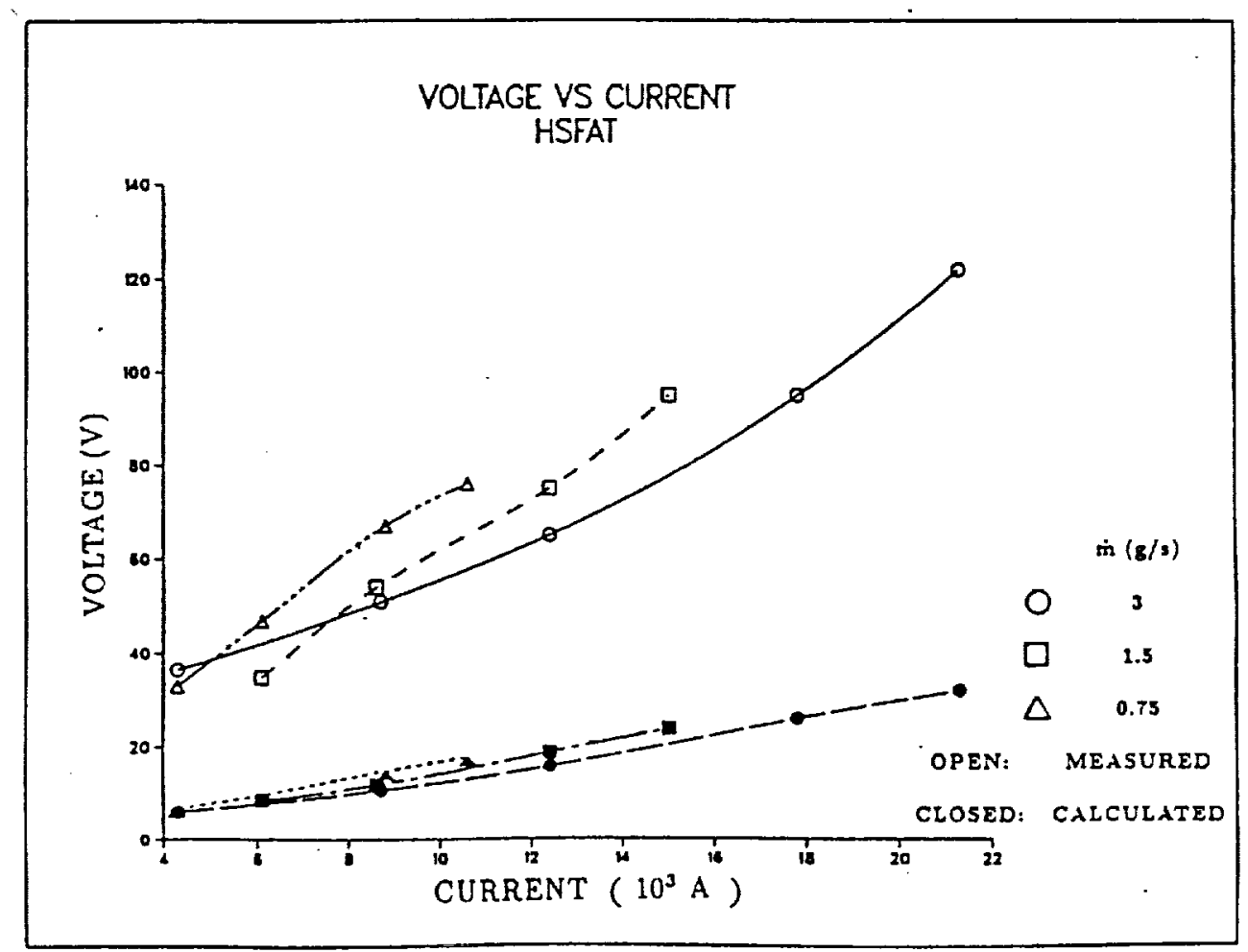

Figure 16. Measured total voltage and predicted plasma voltage for HSFAT thruster, argon propellant. 


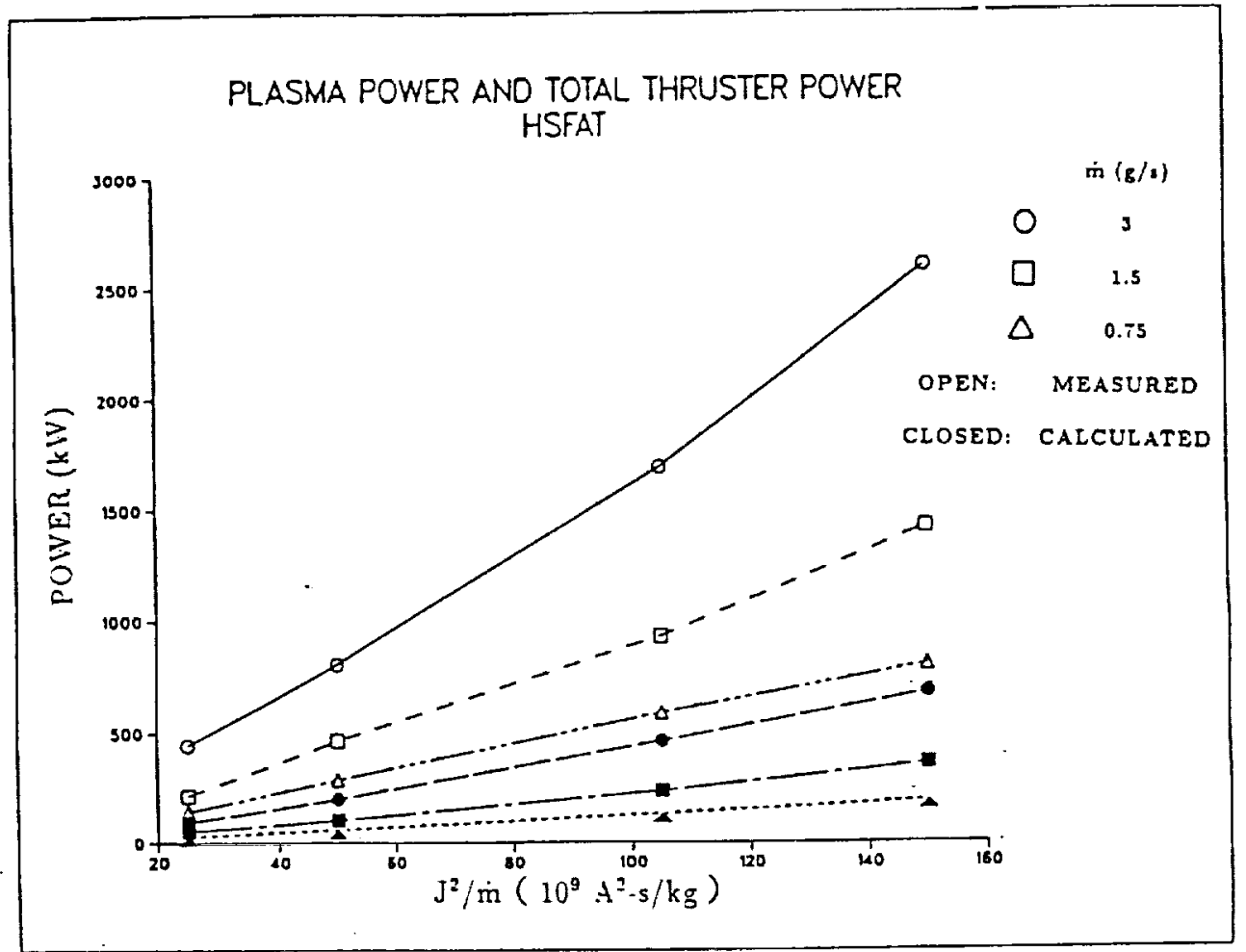

Figure 17. Measured total power and predicted power deposited into plasma for HSFAT thruster, argon propellant.

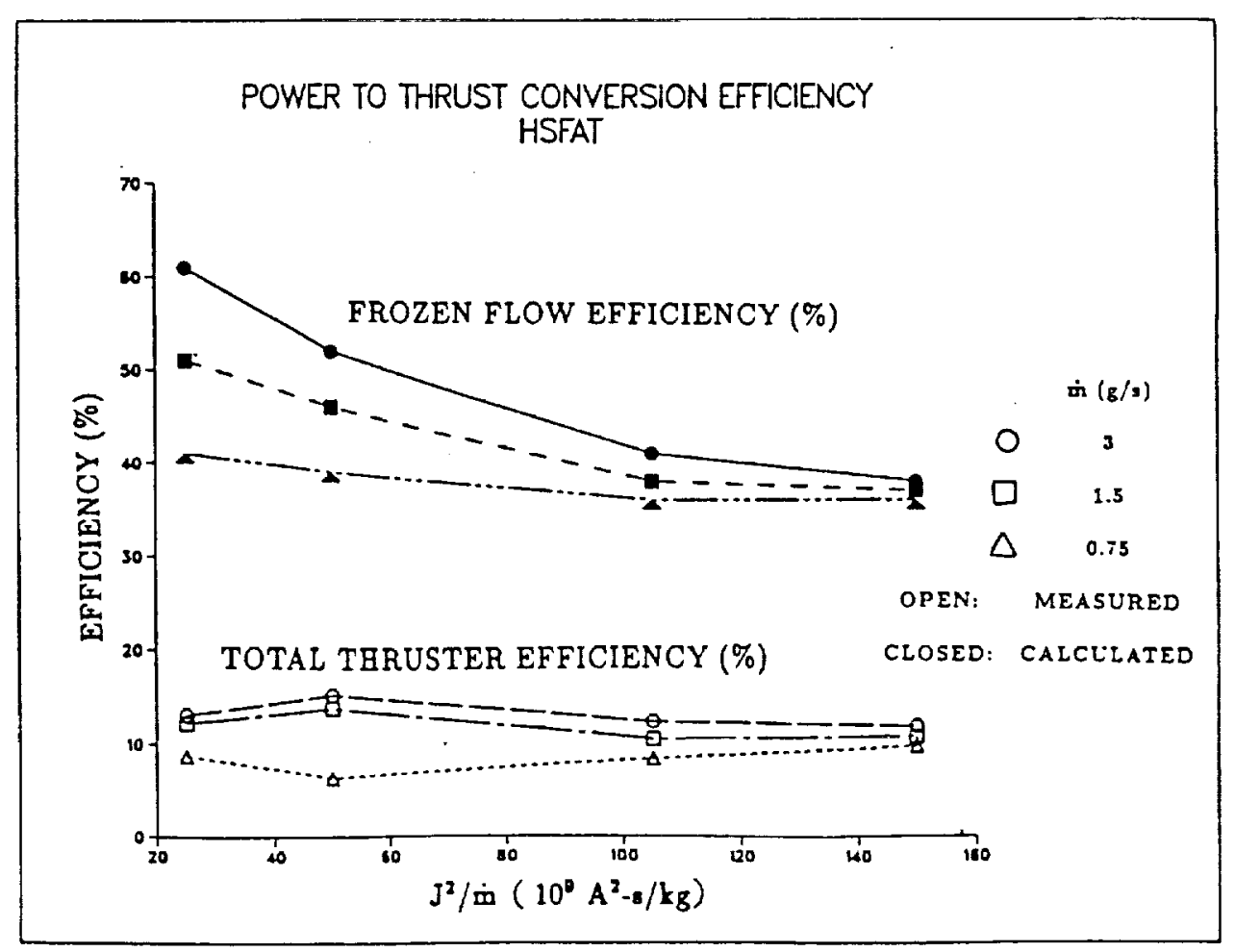

Figure 18. Measured total thruster efficiency and predicted frozen flow efficiency (plasma) for HSFAT thruster, argon propellant. 


\begin{tabular}{|c|c|c|c|}
\hline \multirow{2}{*}{\multicolumn{2}{|c|}{$\begin{array}{l}\text { 4. Title and Subtitle } \\
\text { Numerical Simulation of Self-Field MPD Thrusters }\end{array}$}} & \multicolumn{2}{|l|}{ 5. Report Date } \\
\hline & & \multicolumn{2}{|c|}{ 6. Performing Organization Code } \\
\hline $\begin{array}{l}\text { 7. Author(s) } \\
\text { Michael R. LaPointe }\end{array}$ & & \multicolumn{2}{|c|}{$\begin{array}{l}\text { 8. Performing Organization Report No. } \\
\text { E- } 6440\end{array}$} \\
\hline \multirow{2}{*}{\multicolumn{2}{|c|}{$\begin{array}{l}\text { 12. Sponsoring Agency Name and Address } \\
\text { National Aeronautics and Space Administration } \\
\text { Lewis Research Center } \\
\text { Cleveland, Ohio } 44135-3191\end{array}$}} & \multicolumn{2}{|c|}{$\begin{array}{l}\text { 13. Type of Report and Period Covered } \\
\text { Contractor Report } \\
\text { Final }\end{array}$} \\
\hline & & \multicolumn{2}{|c|}{ 14. Sponsoring Agency Code } \\
\hline \multicolumn{4}{|c|}{$\begin{array}{l}\text { 15. Supplementary Notes } \\
\text { Project Manager, James S. Sovey, Space Propulsion Technology Division, NASA Lewis Research Center, } \\
\text { (216) } 433-2420 \text {. Prepared for the 27th Joint Propulsion Conference cosponsored by the AIAA, SAE, ASME } \\
\text { and ASEE, Sacramento, California, June } 24-27,1991 \text {. }\end{array}$} \\
\hline \multicolumn{4}{|c|}{$\begin{array}{l}\text { 16. Abstract } \\
\text { A fully two dimensional magnetohydrodynamics code has been developed to predict self-field, steady-state MPD } \\
\text { thruster performance. The governing equations are outlined, and methods of solution are presented. Model predictions } \\
\text { are compared with experimental data for two thruster geometries over a range of discharge currents and mass flow } \\
\text { rates. Model limitations are evaluated, and issues concerning quasi-steady versus steady-state thruster comparisons are } \\
\text { discussed. }\end{array}$} \\
\hline $\begin{array}{l}\text { 17. Key Words (Suggested by Author(s)) } \\
\text { Electric propulsion } \\
\text { Numerical analysis } \\
\text { Magnetoplasmadynamics }\end{array}$ & $\begin{array}{r}\text { 18. Distri } \\
\mathrm{I} \\
\mathrm{S}\end{array}$ & $\begin{array}{l}\text { - Unlimited } \\
\text { gory } 64\end{array}$ & \\
\hline $\begin{array}{r}\text { 19. Security Classif. (of the report) } \\
\text { Unclassified }\end{array}$ & $\begin{array}{l}\text { 20. Security Classif. (of this page) } \\
\text { Unclassified }\end{array}$ & $\begin{array}{r}\text { 21. No. of pages } \\
36\end{array}$ & $\begin{array}{r}\text { 22. Price* } \\
\mathrm{A03}\end{array}$ \\
\hline
\end{tabular}

